\title{
Fully Integrated High Gain S-Band Triangular Slot Antenna for CubeSat Communications
}

\author{
Mohamed El Bakkali ${ }^{1}$, Moulhime El Bekkali ${ }^{1}$, Gurjot Singh Gaba ${ }^{2} \mathbb{D}$, Josep M. Guerrero ${ }^{3} \mathbb{D}$, Lavish Kansal ${ }^{2} \mathbb{D}$ \\ and Mehedi Masud $4, *$ (i) \\ 1 National School of Applied Sciences, Sidi Mohamed Ben Abdellah University, Fez 30050, Morocco; \\ mohamed.elbakkali2@usmba.ac.ma (M.E.B.); moulhime.elbekkali@usmba.ac.ma (M.E.B.) \\ 2 School of Electronics \& Electrical Engineering, Lovely Professional University, Punjab 144411, India; \\ gurjot.17023@lpu.co.in (G.S.G.); lavish.kansal@lpu.co.in (L.K.) \\ 3 Center for Research on Microgrids (CROM), Department of Energy Technology, Aalborg University, \\ 9220 Aalborg, Denmark; joz@et.aau.dk \\ 4 Department of Computer Science, College of Computers and Information Technology, Taif University, \\ P.O. Box 11099, Taif 21944, Saudi Arabia \\ * Correspondence: mmasud@tu.edu.sa; Tel.: +966-50-651-6446
}

Citation: El Bakkali, M.; El Bekkali, M.; Gaba, G.S.; Guerrero, J.M.; Kansal, L.; Masud, M. Fully Integrated High Gain S-Band Triangular Slot Antenna for CubeSat Communications.

Electronics 2021, 10, 156. https:// doi.org/10.3390/electronics10020156

Received: 26 November 2020 Accepted: 27 December 2020 Published: 13 January 2021

Publisher's Note: MDPI stays neutral with regard to jurisdictional clai$\mathrm{ms}$ in published maps and institutional affiliations.

Copyright: (C) 2021 by the authors. Licensee MDPI, Basel, Switzerland. This article is an open access article distributed under the terms and conditions of the Creative Commons Attribution (CC BY) license (https:// creativecommons.org/licenses/by/ $4.0 /)$.

\begin{abstract}
Among other CubeSat subsystems, Antenna is one of the most important CubeSat components as its design determines all the telecommunication subsystems' performances. This paper presents a coplanar wave-guide (CPW)-fed equilateral triangular slot antenna constructed and analyzed for CubeSat communications at S-band. The proposed antenna alone presents high gain and ultra-wide band while its radiation pattern is bidirectional at an unlicensed frequency of $2450 \mathrm{MHz}$. The objective is to use the CubeSat chassis as a reflector for reducing the back-lobe radiation and hence minimizing interferences with electronic devices inside the CubeSat. This leads to a high gain of $8.20 \mathrm{dBi}$ and a unidirectional radiation pattern at an industrial, scientific and mdical (ISM) band operating frequency of $2450 \mathrm{MHz}$. In addition to that, the presented antenna is low-profile and exhibits high return loss, ultra-wide impedance bandwidth, and good impedance matching at $2450 \mathrm{MHz}$.
\end{abstract}

Keywords: 3U CubeSat; S-band; slot antenna; coplanar wave-guide (CPW); high gain antennas; unlicensed frequencies; CubeSat body; quasi-Newton method (QNM); antenna localization; optimization

\section{Introduction}

Small satellite (SmallSat) is one of the fast-growing areas in space technologies. They usually present spacecraft ranging from mini-satellites $(100-500 \mathrm{~kg})$ to femto-satellites $(<0.1 \mathrm{~kg})$ [1]. Moreover, the development of modern technologies such as miniaturization, microelectronic, and integrated circuits has enabled SmallSats to be small and capable of ensuring new tasks at a long distance beyond our planet earth. Therefore, the miniaturization of electronic instruments leads to shrinking the satellite size and so cost in satellite launches. On the other hand, there is a tradeoff between physical dimensions and the multifunctional capabilities that a SmallSat can ensure. This paper focuses on the most popular kind of SmallSats, which are the CubeSats [2]. Moreover, the launch costs of this new generation of SmallSats can be minimized by reducing the satellite volume and size of a secondary payload on conventional launch vehicles and hence giving educational institutions, small companies, governments, and even amateurs rational access to space industries [3].

Since the first CubeSats were developed and then launched into space in 2003, thousands of CubeSats have been sent into the low Earth orbit [4]. This rapid progress is due to the short development time, lower complexity, and, most importantly, lower cost of CubeSats than the other satellite families [5]. For instance, our institution, Sidi Mohamed Ben Abdellah University of Fez, Morocco, has developed in the university campus the 
Moroccan First CubeSat (MaSat 1) for climate change in 2019; refer to Appendix A [6]. However, CubeSats should comply with the requirements imposed by CubeSat standardization which makes the design of each CubeSat subsystem a difficult task [7]. The main CubeSat component affected by these limitations is the communication subsystem as it ensures links with earth stations for Uplinking telecommands and downlinking of telemetry and payload data. Therefore, the CubeSat antenna system should have high gain to provide long-distance communications, low profile to occupy small space on the CubeSat's body, and consumes less power [8]. Power is very limited on CubeSats and for all electronic components including antennas it is about $2 \mathrm{~W}$ [2]. This is due to the very limited and restricted number of batteries and solar panels available on CubeSats. Therefore, equipping CubeSats with high-performance and low-profile antennas for long-distance communications and high data rate is more challenging. To deal with this issue, the technology of microstrip and slot antennas is preferred in this study. Due to their low profile, compactness, robustness, and ease of fabrication, patch and slot antennas represent the best choice for connecting CubeSats into orbit with the ground station on earth. They also present low radiation loss, low dispersion, easy matching of input impedance, and are available commercially [9-11]. However, their main drawback is their low peak gain at an operating frequency.

Therefore, this study designs a high-gain and unidirectional small-sized slot antenna for use on 3U-CubeSats around an operating frequency of $2450 \mathrm{MHz}$. This unlicensed frequency band frequency is chosen because it includes two satellite frequency bands (2025$2110 \mathrm{MHz}$ and 2200-2290 MHz) defined by the ECSS (European Cooperation for Space Standardization) for Earth Exploration Satellite services, and the international amateur satellite frequency band $(2400-24500 \mathrm{MHz})$, which is proposed by the ITU (International Telecommunication Union).

In this paper, our antenna approach aims to forward the back-lobe radiation of a slot antenna to increase the antenna gain at an operational frequency of $2450 \mathrm{MHz}$. A small part of the CubeSat's top surface is used as a reflector in this antenna design to obtain that goal. As compared to the implementation of metasurface atop source antennas such as that introduced in [12-15], the proposed antenna design is suitable for all CubeSat configurations, is lightweight, achieves a high gain of $9.70 \mathrm{~dB}$ at an ISM operating frequency of $2450 \mathrm{MHz}$, and occupies less area on the CubeSat bodies.

The rest of this paper is organized as follows: Section 2 introduces our mechanism in designing the proposed equilateral triangular slot antennas. Implementation of the optimized CPW-Fed slot antenna design on the aluminum body of a 3U-CubeSat is presented in Section 3. We discuss and analyze the suitability of the proposed antenna approach for CubeSat communications in Section 4. Section 5 introduces and evaluates the effectiveness of eleven UHF-band and S-band antenna designs proposed by the scientific community for $3 \mathrm{U}$ CubeSats. Then a brief comparison between all proposed antenna designs is provided. Finally, conclusions are given in Section 6.

\section{S-Band Slot Antennas: Antenna Design and Parametric Analysis}

As previously mentioned, the frequency band being targeted in this antenna design is the ISM band at $2450 \mathrm{MHz}$, which is commonly used for CubeSats [16,17]. Therefore, the proposed antenna structure was used on CubeSats for operation at $2450 \mathrm{MHz}$ since the antenna is printed on a $90 \mathrm{~mm} \times 90 \mathrm{~mm}$ FR-4 dielectric $(\varepsilon r=4.4$, $\tan \delta \approx 0.02)$. In this antenna design, ANSYS High Frequency Structure Simulator (HFSS) [18] is used to design and analyze the proposed slot antennas for S-band operation. As it is mentioned in Figures 1-4, all proposed designs are printed on the same dielectric material and radiate through equilateral triangular antennas. The constructed slot antennas were fed by $50 \Omega$ stripe/coplanar wave-guide lines and are printed at two air gap distances, $\mathrm{dg}$ and $\mathrm{d} 0$, from the ground plane. The physical dimensions of proposed slot antennas were calculated using both Finite Element Method (FEM) and quasi-Newton method (QNM) for use on $3 \mathrm{U}$ CubeSats at $2450 \mathrm{MHz}$. ANSYS HFSS uses FEM for electromagnetic simulations, while QNM is an optimization tool integrated with the first one. Tables 1-4 and Appendix B 
achieve physical parameters used in designing proposed slot antennas 1-4, respectively. Therefore, this antenna design describes the proposed low-cost and lightweight CPW-Fed triangular lot antenna for use on CubeSats at S-band.

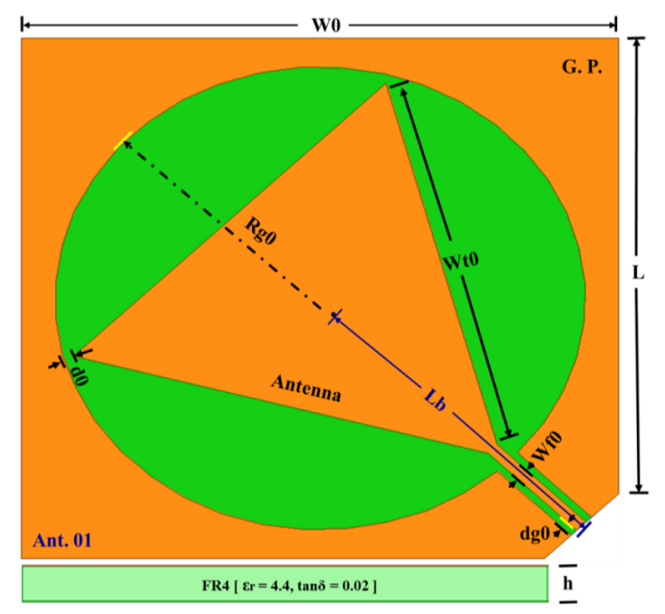

Figure 1. Configuration of the constructed Slot antenna 1.

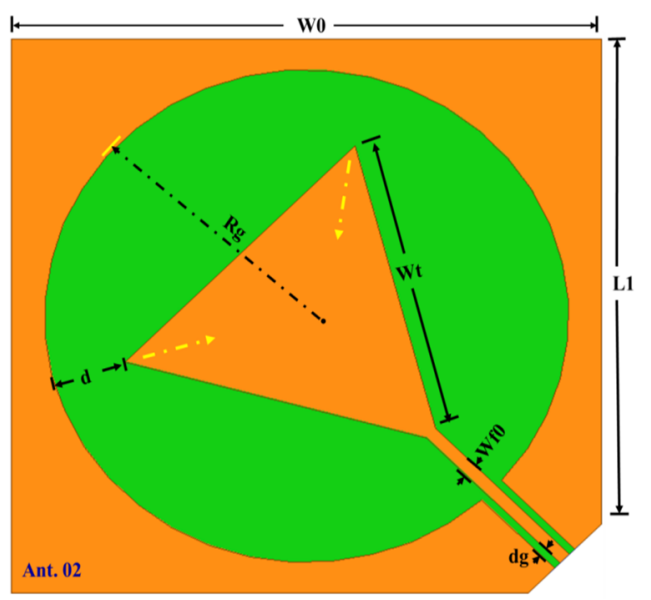

Figure 2. Configuration of the constructed Slot antenna 2.

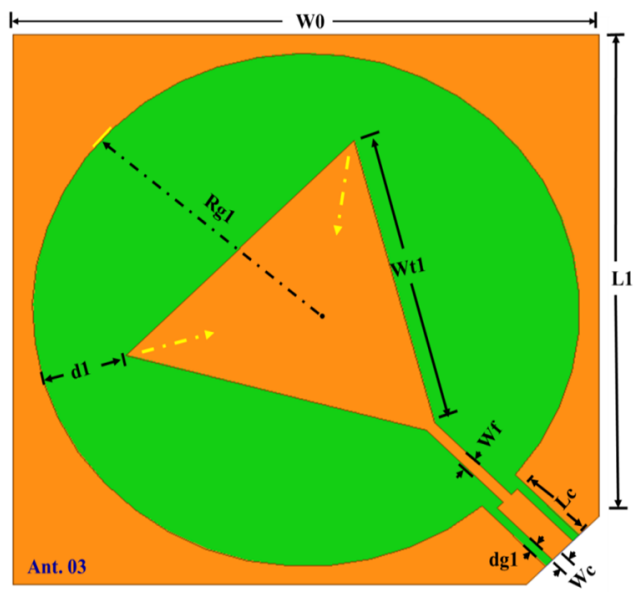

Figure 3. Configuration of the constructed Slot antenna 3. 


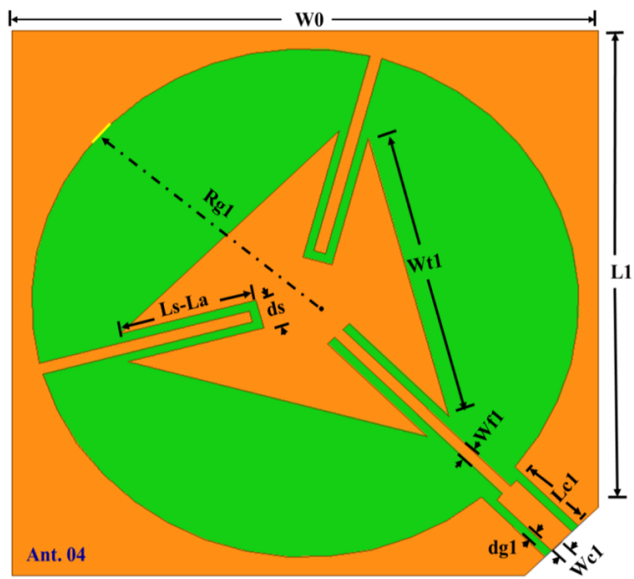

Figure 4. Configuration of the constructed Slot antenna 4.

Table 1. Physical parameters of proposed slot antenna 1.

\begin{tabular}{ccccc}
\hline W & L & Rg0 & Wf0 & Dg0 \\
\cline { 1 - 4 } $90 \mathrm{~mm}$ & $78.77 \mathrm{~mm}$ & $43 \mathrm{~mm}$ & $2 \mathrm{~mm}$ & \\
\hline $\mathrm{Lb}$ & $\mathrm{H}$ & $\mathrm{D} 0$ & Wt0 & $1 \mathrm{~mm}$ \\
\hline $55.7 \mathrm{~mm}$ & $1.6 \mathrm{~mm}$ & $9.65 \mathrm{~mm}$ & $66.69 \mathrm{~mm}$ & \\
\hline
\end{tabular}

Table 2. Geometrical parameters of proposed slot antenna 2.

\begin{tabular}{ccccccc}
\hline W0 & L1 & Rg & Wf0 & D & Wt & Dg \\
\hline $90 \mathrm{~mm}$ & $78.77 \mathrm{~mm}$ & $42 \mathrm{~mm}$ & $2 \mathrm{~mm}$ & $13.55 \mathrm{~mm}$ & $56.88 \mathrm{~mm}$ & $1 \mathrm{~mm}$ \\
\hline
\end{tabular}

Table 3. Physical parameters of proposed slot antenna 3.

\begin{tabular}{ccccc}
\hline W1 & L1 & Rg1 & Wf & Dg1 \\
\cline { 1 - 4 } $90 \mathrm{~mm}$ & $78.77 \mathrm{~mm}$ & $42 \mathrm{~mm}$ & $1.8 \mathrm{~mm}$ & \\
\cline { 1 - 4 } Lc & Wc & D1 & Wt1 & $1 \mathrm{~mm}$ \\
\hline $12 \mathrm{~mm}$ & $0.7 \mathrm{~mm}$ & $13.55 \mathrm{~mm}$ & $56.88 \mathrm{~mm}$ & \\
\hline
\end{tabular}

Table 4. Physical parameters of proposed slot antenna 4.

\begin{tabular}{cccccc}
\hline W0 & L1 & Rg1 & Wf1 & Lc1 & \multirow{2}{*}{ Wc1 } \\
\cline { 1 - 5 } $90 \mathrm{~mm}$ & $78.77 \mathrm{~mm}$ & $42 \mathrm{~mm}$ & $1.8 \mathrm{~mm}$ & $12 \mathrm{~mm}$ & \\
\cline { 1 - 5 } Ds & Ls & La & Wt1 & Dg1 & \multirow{2}{*}{$0.7 \mathrm{~mm}$} \\
\cline { 1 - 5 } $2.9 \mathrm{~mm}$ & $48.5 \mathrm{~mm}$ & $26.93 \mathrm{~mm}$ & $56.88 \mathrm{~mm}$ & $1 \mathrm{~mm}$ & \\
\hline
\end{tabular}

\subsection{S-Band Slot Antenna 1}

To design an equilateral triangular slot antenna suitable for use on CubeSats at an ISM operating frequency of $2450 \mathrm{MHz}$, Slot antenna 1 is proposed in this research work for beginning the design process. The physical parameters listed in Table 1 are used in designing the proposed Slot antenna 1 and are initialized using ANSYS HFSS to design an antenna structure with a size suitable for all CubeSat Configurations. In addition to that, the antenna parameter $\mathrm{Lb}$ is arranged in this study from $44 \mathrm{~mm}$ to $56 \mathrm{~mm}$ to achieve a small reflection coefficient at our operating frequency of $2450 \mathrm{MHz}$, see Figure 5. Moreover, Figures 6 and 7 show Voltage Standing Wave Ratio (VSWR) and real part of the antenna 
input impedance at $2450 \mathrm{MHz}$ as functions of the physical antenna size (i.e., parameter $\mathrm{Lb}$ ), respectively. Therefore, our study in this antenna design approves the effects of $\mathrm{Lb}$ on the slot antenna performances at $2450 \mathrm{MHz}$.

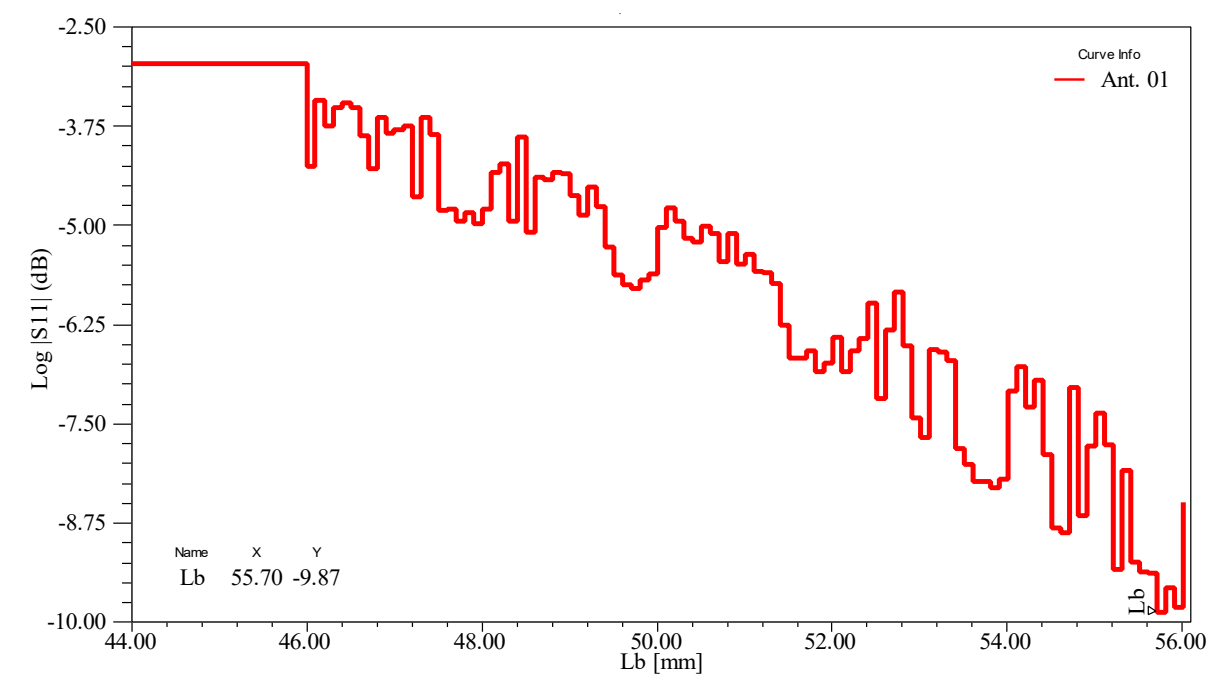

Figure 5. Reflection coefficient of Slot antenna 1 at $2450 \mathrm{MHz}$ versus $\mathrm{Lb}(\mathrm{mm})$.

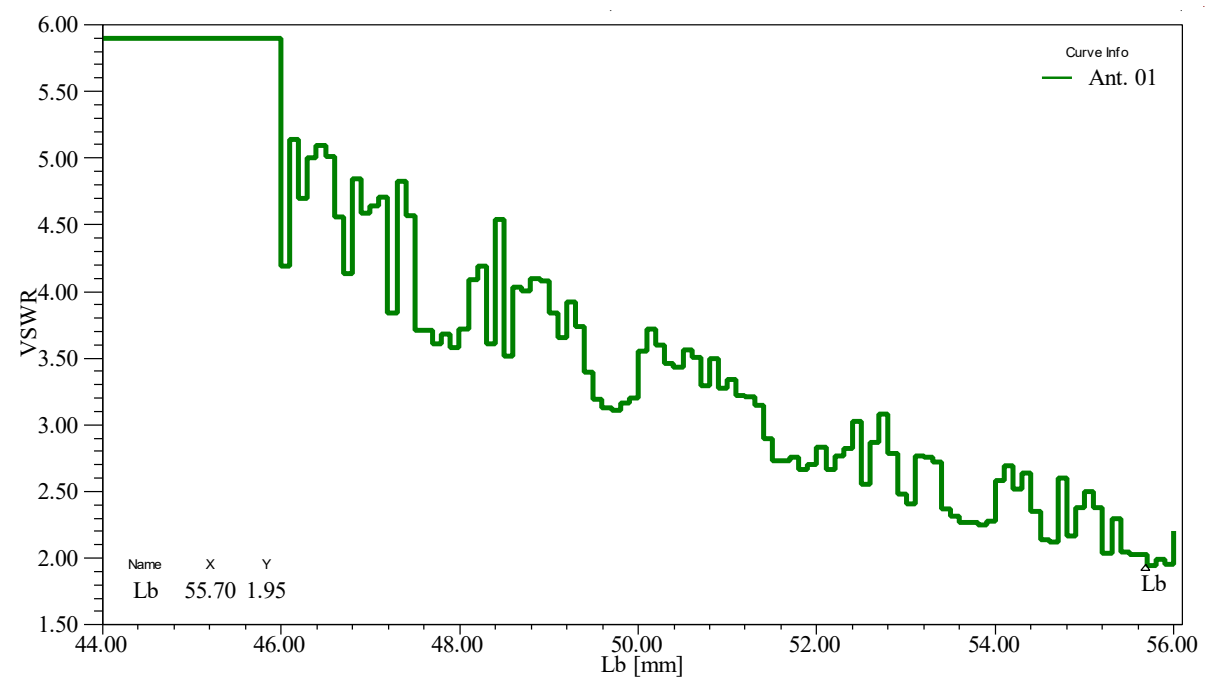

Figure 6. VSWR (Voltage Standing Wave Ratio) of Slot antenna 1 at $2450 \mathrm{MHz}$ versus Lb (mm).

Results shown in Figures 5-7 conclude, therefore, that each of the reflection coefficient, VSWR, and the input impedance real part of proposed Slot antenna 1 evolve inversely with the antenna full size at our target operating frequency of $2450 \mathrm{MHz}$ and achieve the smallest when $\mathrm{Lb}=55.7 \mathrm{~mm}$. In this case, the proposed Slot antenna 1 presents a return loss close to $10 \mathrm{~dB}$, VSWR of 1.95, and input impedance with a real part of $92 \Omega$ at $2450 \mathrm{MHz}$. These results indicate the antenna physical size that can achieve good performances for CubeSat communications at $2450 \mathrm{GHz}$ with suitability for all CubeSat configurations.

Conclusions and results of our study in this antenna design 1 will be used as the background of our antenna design 2 in the next subsection, which is proposed to obtain high return loss and small VSWR at the same operating frequency of $2450 \mathrm{MHz}$. 


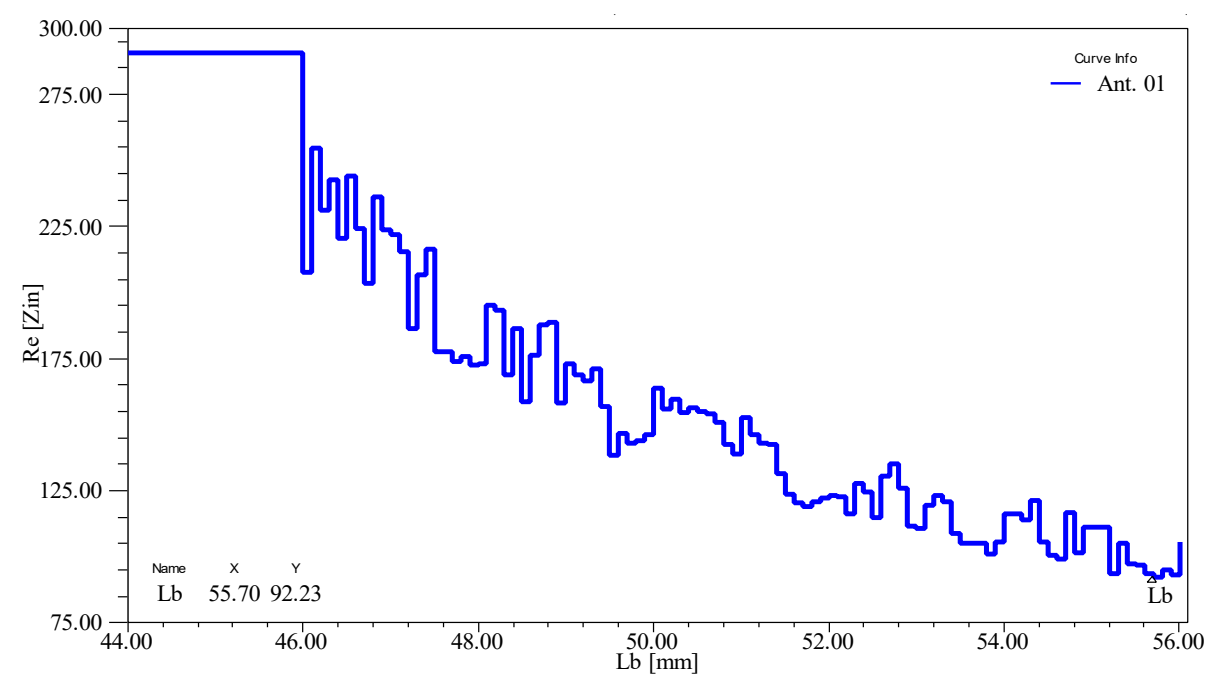

Figure 7. Real part of input impedance of Slot antenna 1 at $2450 \mathrm{MHz}$ versus $\mathrm{Lb}$ (mm).

\subsection{S-Band Slot Antenna 2}

The previous subsection shows that the area occupied by the proposed Slot antenna 1 affects the antenna performances at our working frequency of $2450 \mathrm{MHz}$. In antenna design 01, the best Return Loss (RL) at $2450 \mathrm{MHz}$ is close to $10 \mathrm{~dB}$ and is achieved at $\mathrm{Lb}$ $=55.70 \mathrm{~mm}$. Henceforth, new optimization techniques can be applied to the proposed antenna configuration to improve Slot antenna 1. Figure 2 depicts the configuration of the Slot antenna 2 presented in this subsection. In this antenna design, the ground plane, a rectangular perfect electric conductor is slotted by a circular slot located at the antenna center and has an $\mathrm{Rg}$ radius. Therefore, both the ground plane and the triangular radiating element are separated from each other by two varied distances, $\mathrm{d}$ and $\mathrm{dg}$, and are printed on the dielectric material's top face. Electromagnetic coupling between the ground plane and proposed triangular antenna is affected by each of $\mathrm{Rg}, \mathrm{dg}$, and $\mathrm{d}$. The third antenna dimension $\mathrm{d}$ is initialized at $5 \mathrm{~mm}$, and the others are optimized using QNM. The overall antenna has a lateral dimension of $90 \times 90 \mathrm{~mm}^{2}$ which makes our design suitable for all CubeSat structures, including the $3 \mathrm{U}$ configuration, which is our case and is analyzed using geometrical parameters listed in Table 2. Figures 8 and 9 present reflection coefficient and VSWR of the proposed slot antenna 2, respectively.

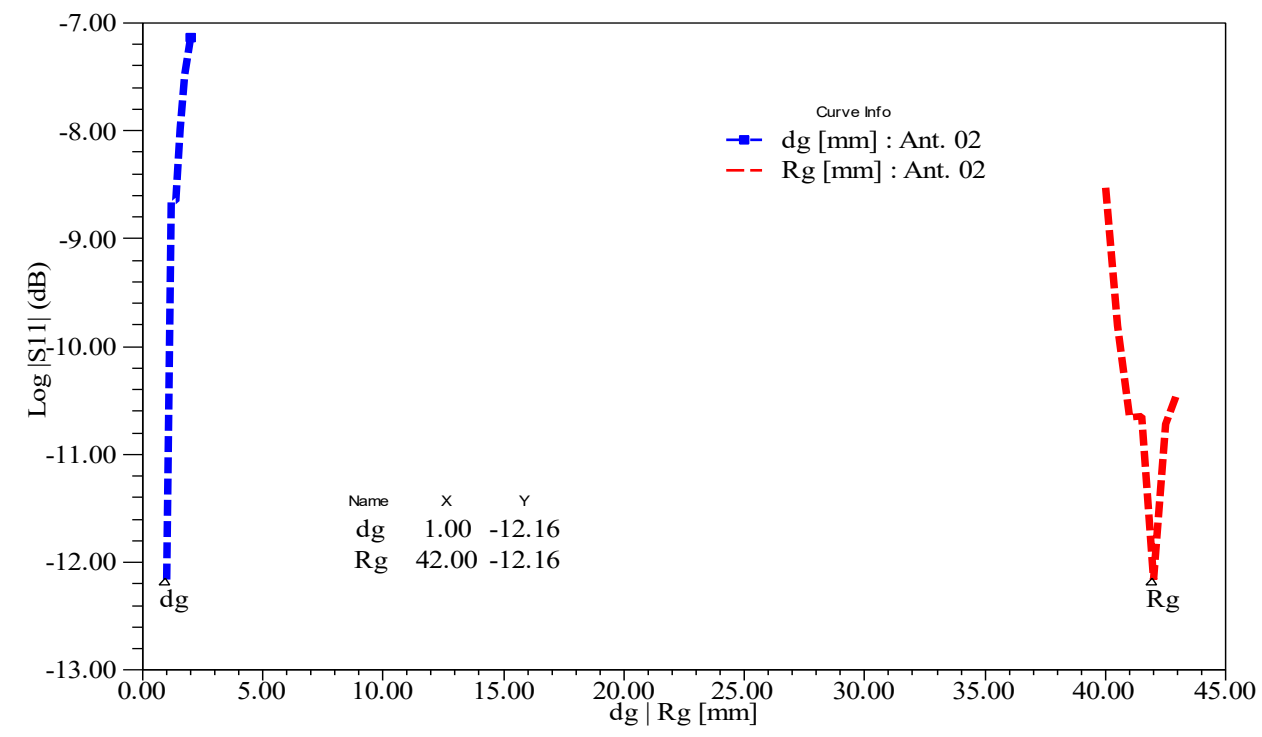

Figure 8. Reflection coefficient of Slot antenna 2 at $2450 \mathrm{MHz}$ versus dg and $\mathrm{Rg}(\mathrm{mm})$. 


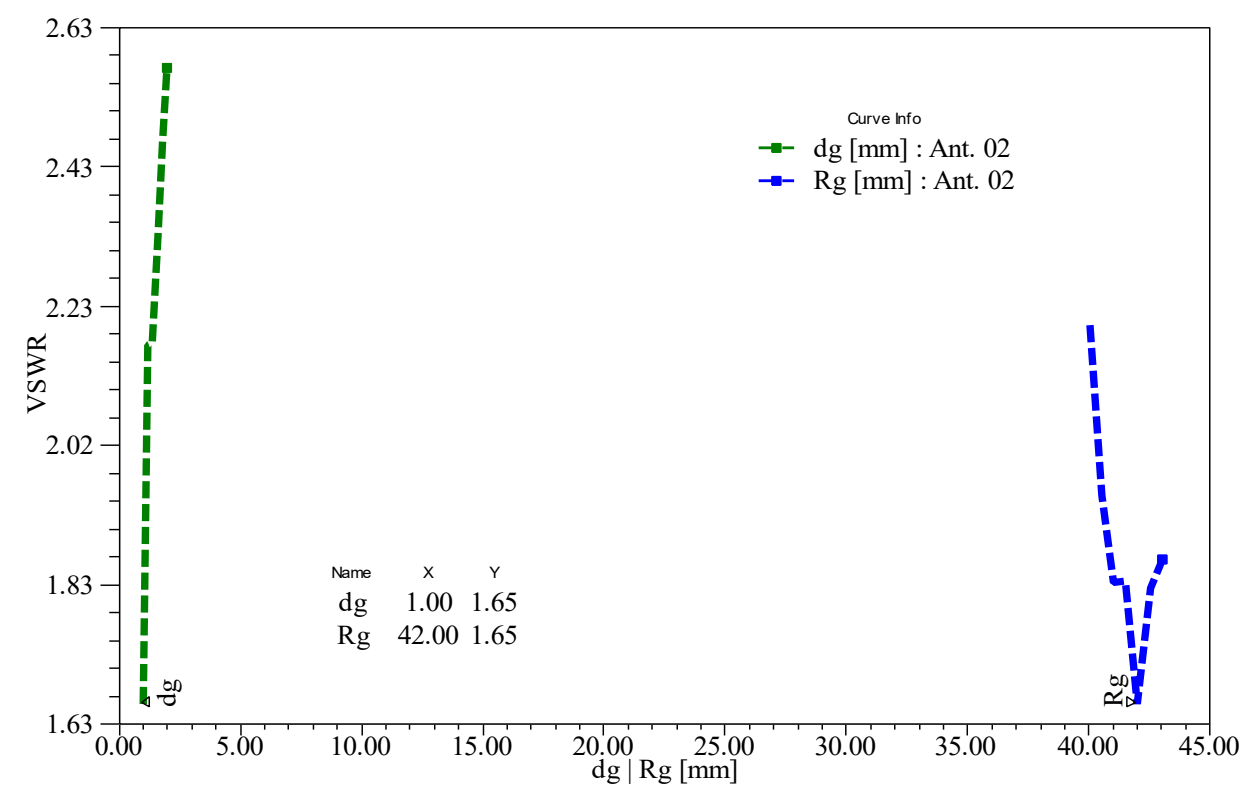

Figure 9. VSWR of Slot antenna 2 at $2450 \mathrm{MHz}$ versus dg and $\mathrm{Rg}(\mathrm{mm})$.

Slot antenna 2 shows that the air gap distances between the triangular antenna improve both RL and VSWR of proposed Slot antenna 1 at $2450 \mathrm{MHz}$ when $\mathrm{dg}=1 \mathrm{~mm}$ and $\mathrm{Rg}=42 \mathrm{~mm}$. Therefore, Slot antenna 2 presents an RL well above $10 \mathrm{~dB}$ (reflection coefficient of $-12.16 \mathrm{~dB}$ ) and VSWR well below 2 (VSWR of 1.65) at 2450. Consequently, the proposed approach in antenna design 2 enhances both return loss and VSWR of Slot antenna 1 at our CubeSat operating frequency of $2450 \mathrm{MHz}$ using only the antenna-ground plane air gap distances in this parametric study.

Hence, this approach gives an RL above $10 \mathrm{~dB}$ (reflection coefficient below $-10 \mathrm{~dB}$ ), VSWR less than 2 at $2450 \mathrm{MHz}$, and occupies a full area suitable for all CubeSat structures; the antenna configuration is fed using only a $50 \Omega$ strip line. Henceforth, achieved results of Slot antenna 2 can be improved to obtain higher RLs, VSWR close to one, and good impedance matching at $2450 \mathrm{MHz}$ using another way of antenna excitation taken into consideration low power on CubeSats in the outer space. In addition to that, low reflected power is handled in this research work to achieve low power consumption and minimize interferences generated by back lobe radiations with the other CubeSat subsystems.

\subsection{S-Band Slot Antenna 3}

As mentioned previously, both Slot antenna 1 and Slot antenna 2 are excited using $50 \Omega$ stripe lines, while both full antenna area and air gap distances between the triangular antenna and ground plane are used to optimize the proposed antenna performances at $2450 \mathrm{MHz}$. In this antenna design, proposed results of previous designs at $2450 \mathrm{MHz}$ with suitability for all CubeSat configurations, a $50 \Omega$ coplanar wave-guide with a width of Wc and length of Lc is used to excite the Slot antenna 3. The Triangular antenna obtains excitation power from the CPW-Fed line through a transition line having with of Wf. The triplet (Wc, Lc, Wf) is optimized at $2450 \mathrm{MHz}$ using QNM to achieve higher return losses (lower reflection coefficients), wide impedance bandwidth, good impedance matching, and high gain for CubeSat communications. The proposed Slot antenna 3 is designed using physical dimensions given by Table 3, and results of proposed QNM optimization and parametric study are introduced in terms of reflection coefficient and VSWR shown in Figures 10 and 11, respectively. 


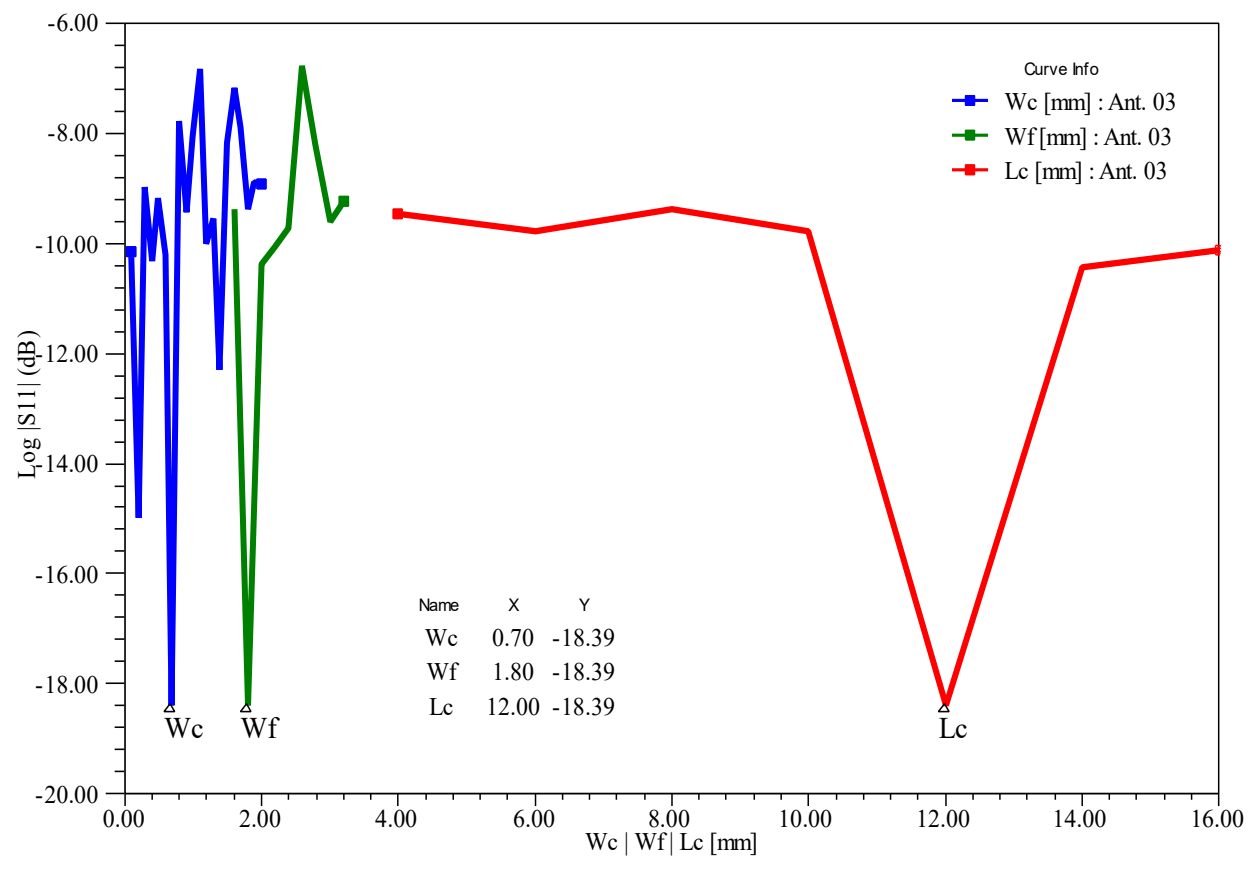

Figure 10. Reflection coefficient of Slot antenna 3 at $2450 \mathrm{MHz}$ versus Wc, Wf, and Lc $(\mathrm{mm})$.

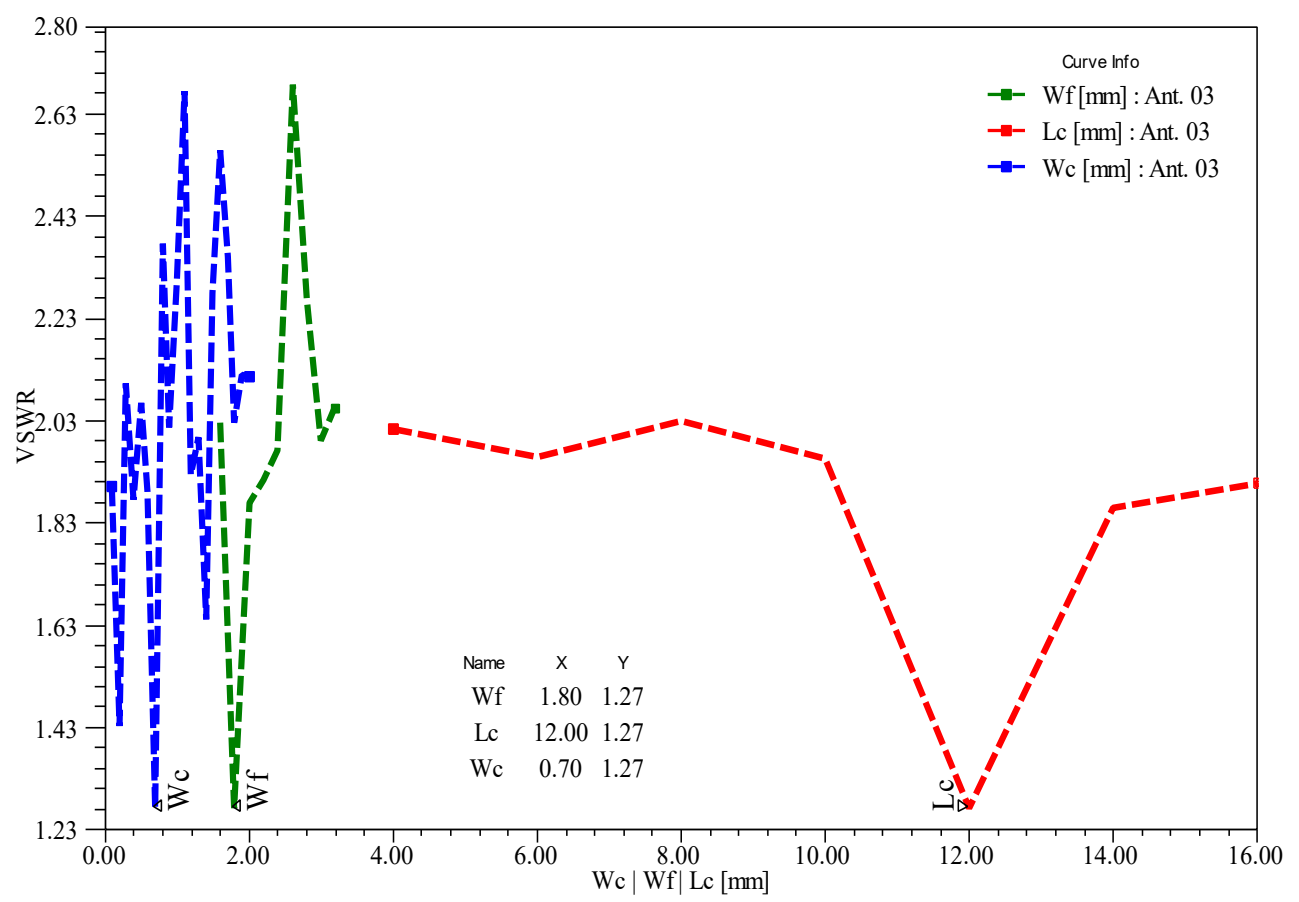

Figure 11. VSWR of Slot antenna 3 at $2450 \mathrm{MHz}$ versus Wc, Wf, and Lc (mm).

We show that the proposed CPW-Fed Slot antenna 3 achieves RL above $10 \mathrm{~dB}$ (reflection coefficients below -10 dB) and VSWR less than 2 at $2450 \mathrm{MHz}$ for many triplets of (Wc; Wf; Lc). The lowest of both antenna parameters are defined when $\mathrm{Wf}=1.80 \mathrm{~mm}$, $\mathrm{Wc}=0.70 \mathrm{~mm}$, and $\mathrm{Lc}=12 \mathrm{~mm}$. The optimal solution of proposed QNM optimization program is characterized by $\mathrm{Wf}=1.80 \mathrm{~mm}, \mathrm{Wc}=0.70 \mathrm{~mm}$, and $\mathrm{Lc}=12 \mathrm{~mm}$, with RL of $18.39 \mathrm{~dB}$ (reflection coefficient of $-18.39 \mathrm{~dB}$ ), VSWR of 1.27 (close to one) at $2450 \mathrm{MHz}$. These results are appropriate for CubeSats and prove that the proposed CPW feed line enforces maximum quantity of excitation power to the triangular antenna and hence that 
low power is being reflected to the excitation source. This benefit is of great importance for CubeSats where electric power is, as mentioned previously, very limited.

Figure 12 shows that the optimized structure of CPW-Fed Slot antenna 3 gives an RL of well above $18 \mathrm{~dB}$, input impedance close to $61 \Omega$, and wide impedance bandwidth $850 \mathrm{MHz}(2140-2990 \mathrm{MHz})$ around our ISM operating frequency of $2450 \mathrm{MHz}$. Moreover, this antenna configuration presents a very low reflection coefficient of $-40 \mathrm{~dB}$, an ideal VSWR of 1.02, and good impedance matching with an input impedance of 50.56-j0.74 $\Omega$ at $2580 \mathrm{MHz}$. Therefore, the CPW-Fed Slot antenna 3 achieves very suitable return loss, bandwidth, and impedance matching for use on CubeSats at $2580 \mathrm{MHz}$, while an essential portion of electric power is reflected in the excitation source at $2450 \mathrm{MHz}$. From another hand, this antenna design 3 radiates bidirectionally despite the presented high gain of $6.28 \mathrm{~dB}$ at $2450 \mathrm{MHz}$, see Figure 13.

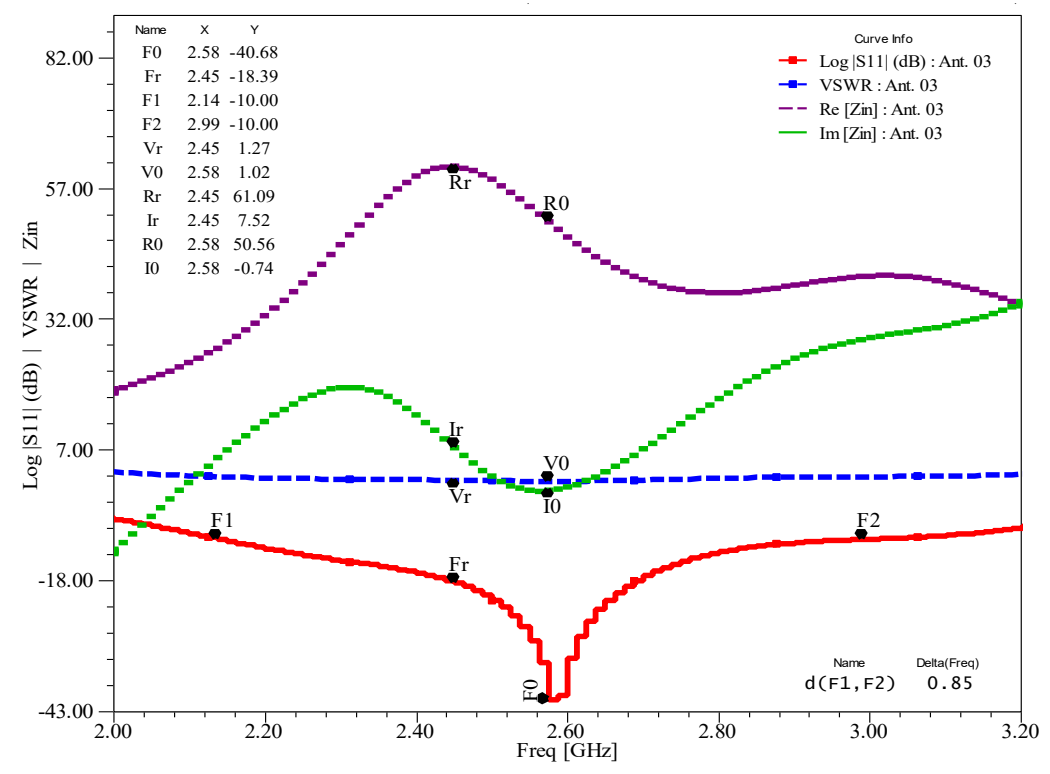

Figure 12. Reflection coefficient, VSWR, and input impedance of Slot antenna 3 versus frequency.

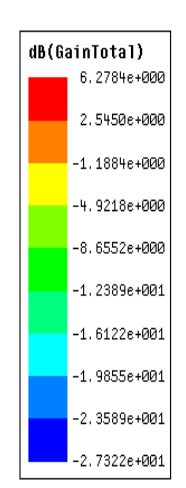

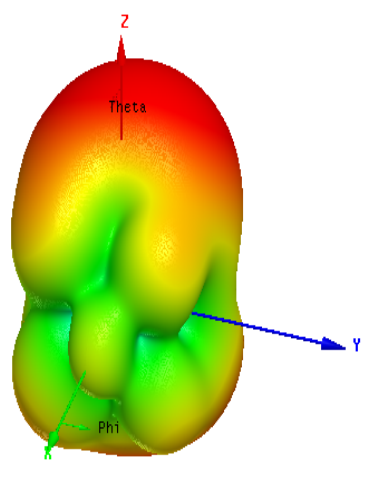

(a)

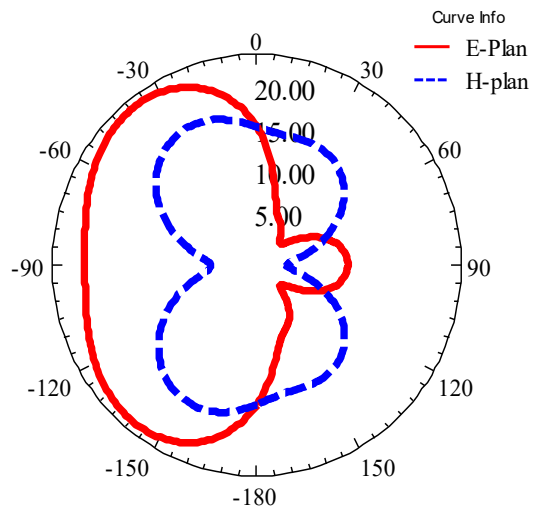

(b)

Figure 13. 3D gain, E- and H-fields of Slot antenna 3 at $2450 \mathrm{MHz}$ : phi $=0^{\circ} ; 90^{\circ}$. (a) 3D gain at $2450 \mathrm{MHz}$; (b) E- and H-fields at $2450 \mathrm{MHz}$ : phi $=0^{\circ} ; 90^{\circ}$.

Our approach in antenna design 3 presents a $50 \Omega$ CPW strip line as a low-power and low-cost feeding method to excite. The proposed CPW-Fed Slot antenna 3 is a lightweight, low-cost, small-size, and high-gain antenna configuration. It can be used as a good candidate for CubeSat communications at long-distance communications. However, reflected power to the excitation source and back lobe radiations at $2450 \mathrm{MHz}$ minimize the effective- 
ness of the proposed CPW-Fed Slot antenna 3 and generate interferences with electronic devices inside the CubeSat box and then minimize the effectiveness of proposed Slot antenna 3. These RF issues can be solved and so re-direct/re-enforce radiating energy in the outer space using slots in the triangular antenna or the CubeSat body as reflector.

\subsection{S-Band Slot Antenna 4}

Figure 4 depicts the configuration of the proposed CPW-Fed Slot antenna 4. In this antenna structure, the CPW-Fed Slot antenna 3 is slotted using three rectangular notches to obtain good impedance matching and so very low reflected power to the excitation source at our CubeSat operating frequency of $2450 \mathrm{MHz}$. The three notches are inclined from each other by an angle of $120^{\circ}$ in order to define our targets of very low reflection coefficient (very high return loss) and input impedance close to $50 \Omega$ at $2450 \mathrm{MHz}$ with wide $-10 \mathrm{~dB}$ bandwidth. The proposed notches are characterized by their physical width of ds and physical length of (LS-La), which are optimized in this approach using QNM. The CPW-Fed Slot antenna 4 is, henceforth, designed using dimensions given in Table 4. In addition to that, a parametric study is then introduced in this approach for ds and Ls ranging from $1 \mathrm{~mm}$ and $30 \mathrm{~mm}$ to $4 \mathrm{~mm}$ and $50 \mathrm{~mm}$, respectively. Reflection coefficient, VSWR, and an input impedance of CPW-Fed slot antenna 4 are analyzed as functions of ds and Ls and are depicted in Figures 14-16, respectively.

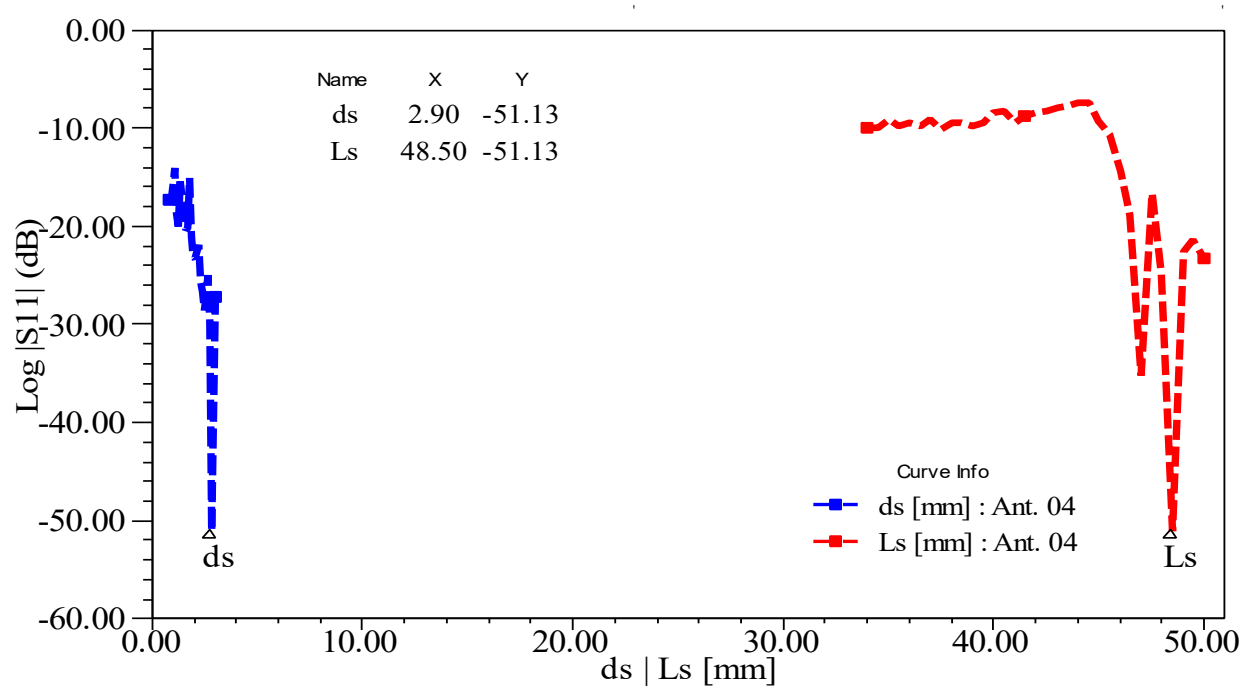

Figure 14. Reflection coefficient of slot antenna 4 at $2450 \mathrm{MHz}$ versus ds and Ls (mm).

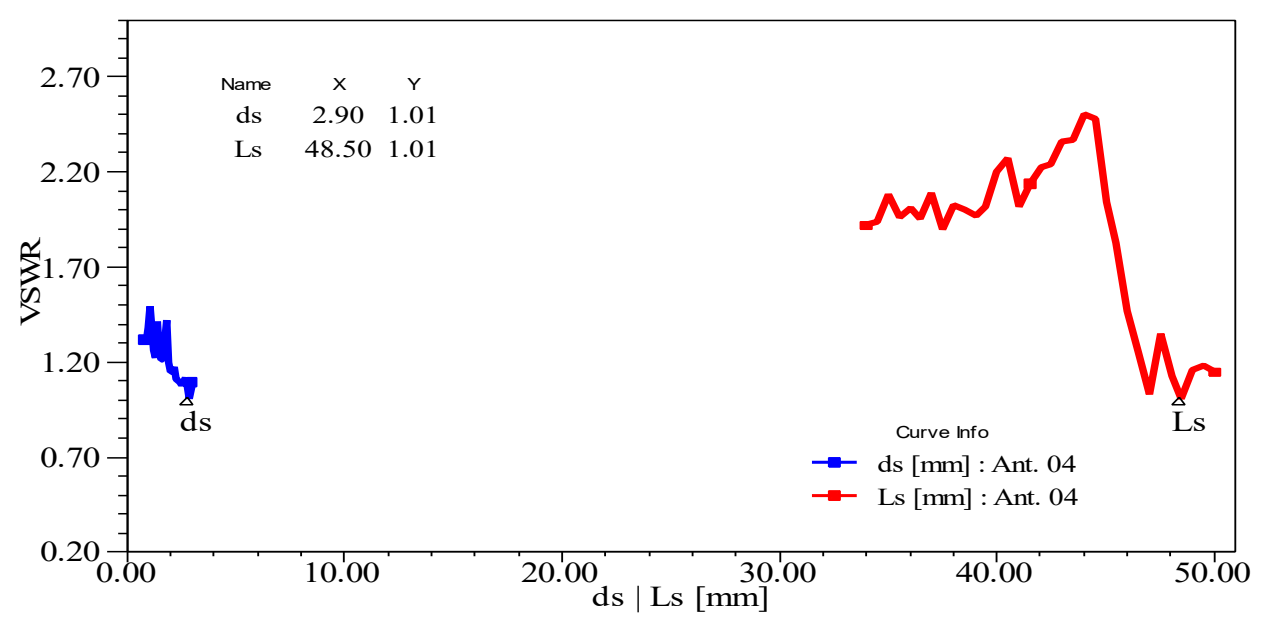

Figure 15. VSWR of slot antenna 4 at $2450 \mathrm{MHz}$ versus ds and Ls (mm). 


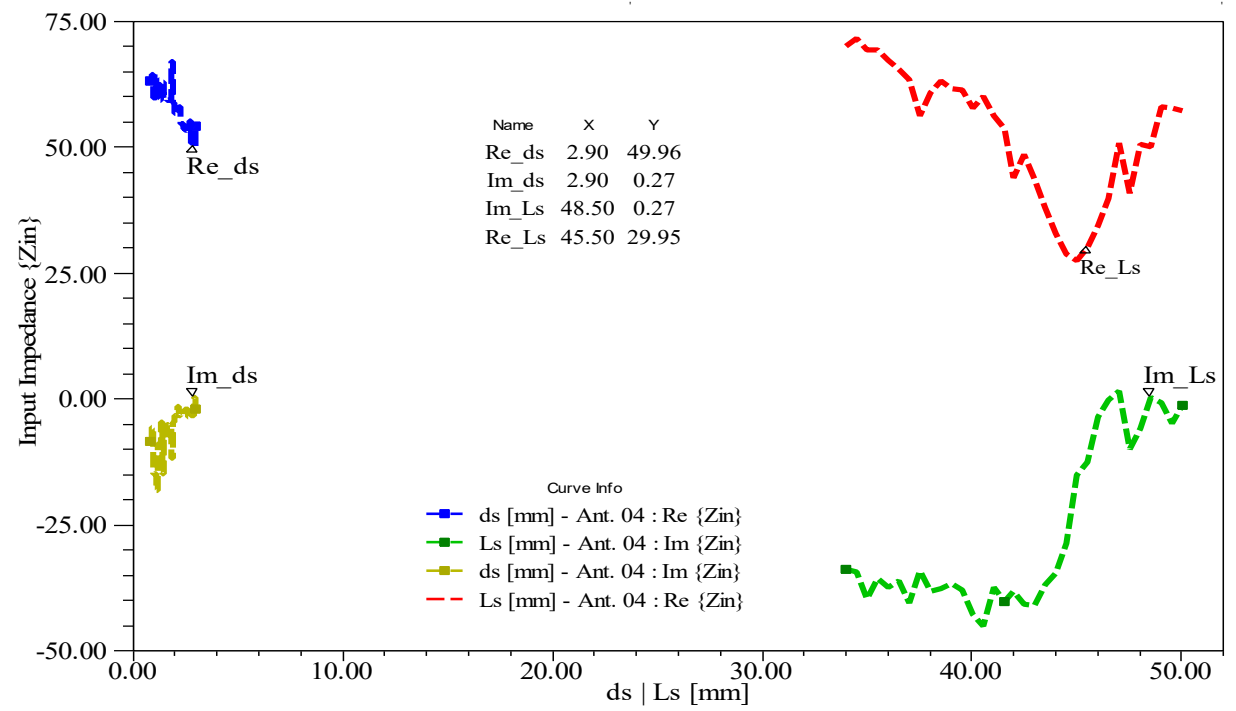

Figure 16. Input impedance of Slot antenna 4 at $2450 \mathrm{MHz}$ versus ds and Ls (mm).

Through the achieved results, it is proved that the CPW-Fed Slot antenna 4, which is the optimized configuration of proposed slot antenna designs in this research work, gives a reflection coefficient well below $-20 \mathrm{~dB}$ at $2450 \mathrm{MHz}$ for ds and Ls ranging from $2 \mathrm{~mm}$ and $45 \mathrm{~mm}$ to $4 \mathrm{~mm}$ and $50 \mathrm{~mm}$, respectively. These results are conformed by VSWR close to one and good impedance matching at around the same operating frequency and for the same values of ds and Ls. In addition to that, CPW-Fed Slot antenna 4 presents a very low reflection coefficient of $-51.13 \mathrm{~dB}$ (very high return loss of $51.13 \mathrm{~dB}$ ), quasi-ideal VSWR of 1.01 , and good impedance matching with an input impedance of about $50 \Omega$ at $2450 \mathrm{MHz}$ when $\mathrm{Ls}=48.5 \mathrm{~mm}$ and $\mathrm{ds}=2.9 \mathrm{~mm}$. Therefore, the proposed approach of CPW-Fed Slot antenna 4 solved the RF problem of reflected power in this research work and so all excitation power is moved to the triangular Slot antenna 4 and then radiated into space. The proposed CPW-Fed Slot antenna 4, consequently, ensures wide impedance bandwidth ranging from $2210 \mathrm{MHz}$ to $2900 \mathrm{MHz}(-10 \mathrm{~dB}$ BW of $800 \mathrm{MHz}$ ) with minimal reflection coefficient of $-51.39 \mathrm{~dB}$, VSWR close to one, and good impedance matching at our ISM operating frequency of $2450 \mathrm{MHz}$; refer to Figure 17.

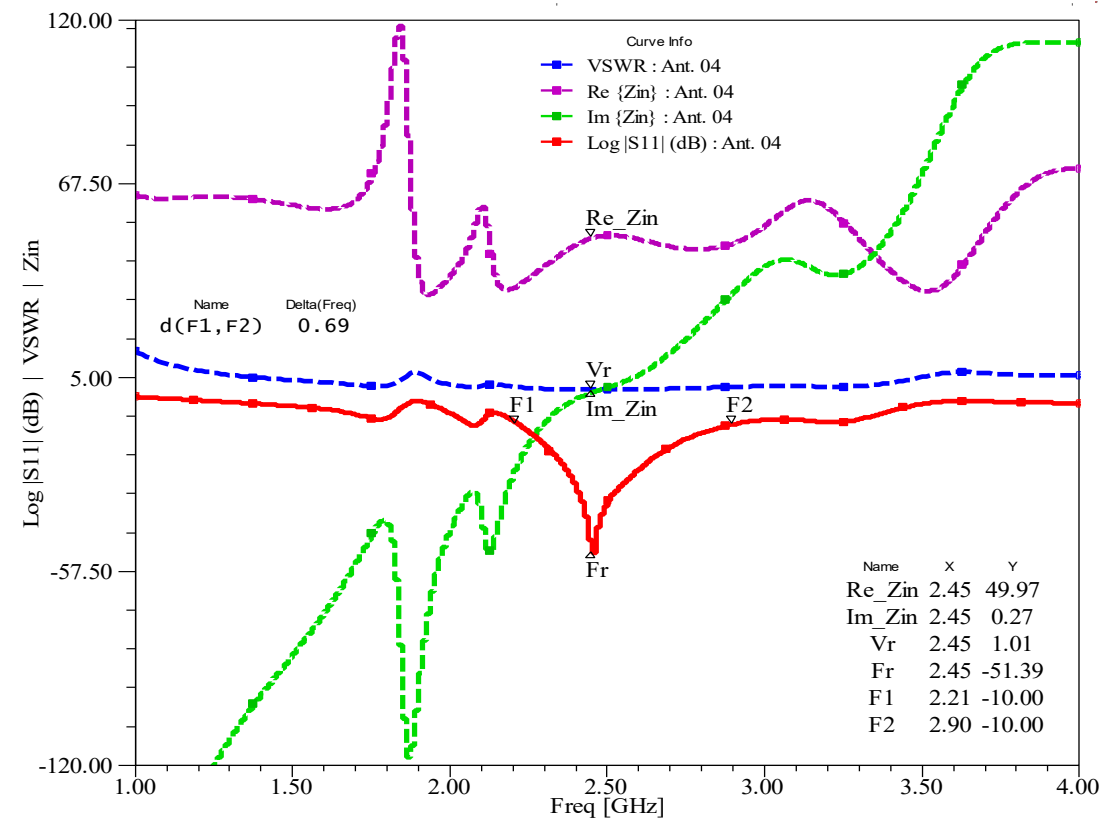

Figure 17. Reflection coefficient, VSWR, and input impedance of Slot antenna 4 versus frequency. 
Figures 18 and 19 demonstrate that the proposed CPW-Fed Slot antenna 4 presents the good distribution of E-field that shows radiation of maximum energy using the optimized triangular radiating antenna, high gain of $6.17 \mathrm{~dB}$, while the radiation pattern is still bidirectional at $2450 \mathrm{MHz}$.

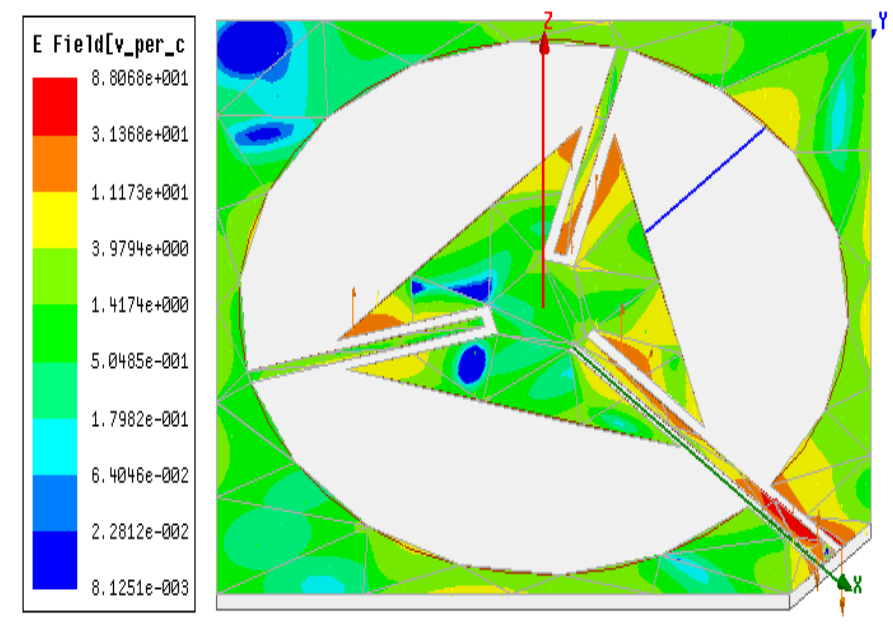

Figure 18. Distribution of E-field of Slot antenna 4 at $2450 \mathrm{MHz}$.

Consequently, this research work introduces, designs, analyses, and optimizes a highgain and low-profile CPW-Fed slot antenna for use on CubeSats at S-band. The final design presents very efficient results of return loss, impedance matching, $-10 \mathrm{~dB}$ bandwidth, and gain using QNM, three notches, and a $50 \Omega \mathrm{CPW}$ feed line in exciting the proposed slot antenna. However, the radiation pattern is still bidirectional at $2450 \mathrm{MHz}$, and so interferences with the other electronic components inside the CubeSat box are still important in this antenna design. Resolution of this RF issue presents an opportunity to enhance the gain at our CubeSat targeting frequency of $2450 \mathrm{MHz}$ using metallic reflector to re-direct the back-lobe radiations outside the CubeSat chassis.

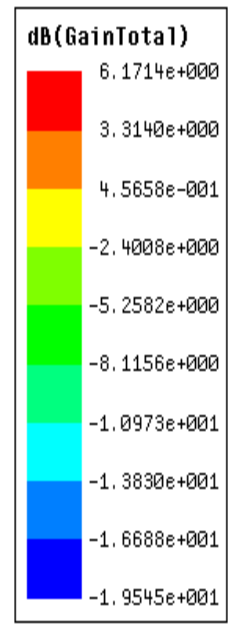

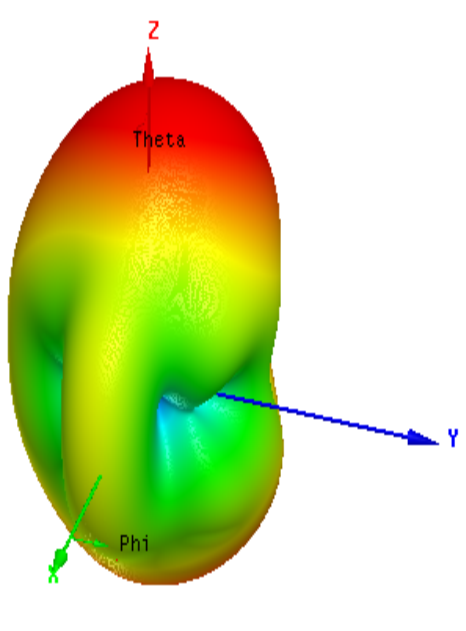

(a)

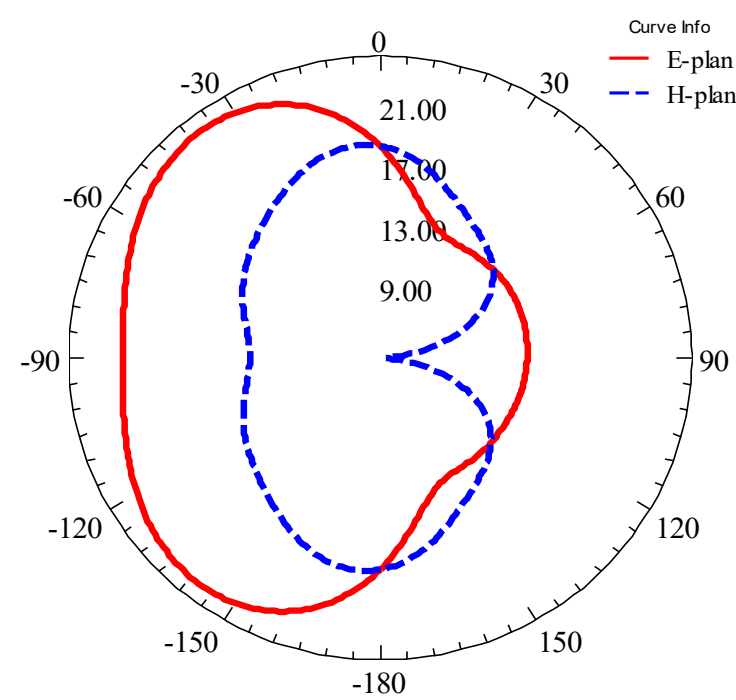

(b)

Figure 19. 3D gain, E- and H-fields of Slot antenna 4 at $2450 \mathrm{MHz}$ : (a) 3D gain plot at $2450 \mathrm{MHz}$; (b) E- and H-fields at $2450 \mathrm{MHz}$. 


\section{Full Satellite: CPW-Fed Slot Antenna $4+3$ U CubeSat}

In this section, the RF issue of back lobe radiation introduced by the proposed CPWFed slot antenna is solved using a small metallic part of the CubeSat's top face below the antenna backside to re-radiate the back-lobe radiations outside the CubeSat box and then improve the peak gain at $2450 \mathrm{MHz}$; refer to Figure 20. Therefore, this approach studies the effects of the CubeSat body on antenna performances along X-, Y-, and Z-axis. It defines the optimal position that can permit the proposed antenna design to present unidirectional radiation with better than $8 \mathrm{dBi}$ at $2450 \mathrm{MHz}$.

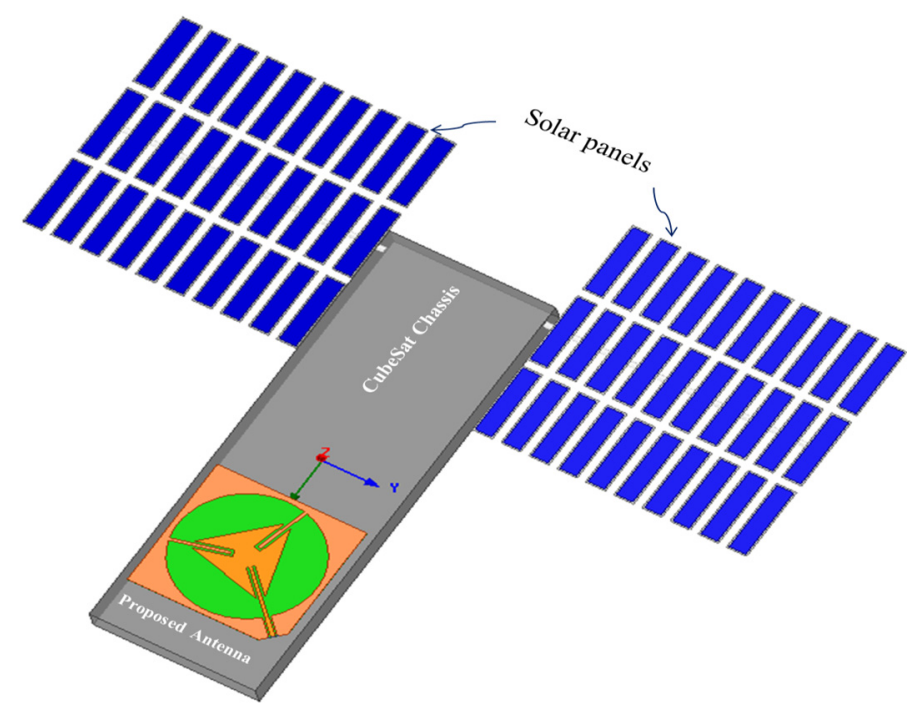

Figure 20. 3D HFSS model of the proposed full system (3U CubeSat + Slot antenna 4).

The highest gain at $2450 \mathrm{MHz}$ is achieved by shifting an air gap distance of Ha mm between the CubeSat's chassis and the antenna dielectric. This air gap distance, which is the position of the proposed antenna along the Z-axis, is optimized using QNM and shows the effects of antenna displacement along the $Z$-axis on the full satellite performances, which are also studied along the $\mathrm{X}$-axis and $\mathrm{Y}$-axis in this research work. Henceforth, our full satellite's antenna performances are calculated and analyzed in this study as functions of displacement of proposed CPW-Fed slot antenna along X-axis, Y-axis, and Zaxis. Figure 21 illustrates our proposed full satellite's reflection coefficients as functions of air gap distance $\mathrm{Ha}$, positions along $\mathrm{X}$-axis, and $\mathrm{Y}$-axis, respectively.

We observe that the proposed CPW-Fed slot antenna mounted on the CubeSat chassis can achieve reflection coefficients below $-10 \mathrm{~dB}$ at $2450 \mathrm{MHz}$ along $\mathrm{X}$-axis for $\mathrm{x}=-3 \mathrm{~cm}$, $4 \mathrm{~cm}$, and for positions ranging from $-7.92 \mathrm{~cm}$ and $4.8 \mathrm{~cm}$ to $-7.06 \mathrm{~cm}$ and $5.94 \mathrm{~cm}$, respectively. The lowest is given at $-7.5 \mathrm{~cm}$ with a small reflection coefficient of $-22.36 \mathrm{~dB}$. Along the Y-axis, our proposed full satellite presents reflections well below $-10 \mathrm{~dB}$ for $\mathrm{Y}$ ranging from $0.5 \mathrm{~cm}$ to $5 \mathrm{~cm}$ with a lowest of $-22.36 \mathrm{~dB}$ at $\mathrm{y}=5 \mathrm{~cm}$ from the CubeSat tope face center. On the other hand, air gap distance, $\mathrm{Ha}$, between the CubeSat tope face and backside of the proposed CPW-Fed slot antenna achieves a high return loss of $22.36 \mathrm{~dB}$ (reflection coefficient of $-22.36 \mathrm{~dB}$ ) at $\mathrm{Ha}=16.8 \mathrm{~mm}$ and reflection coefficients well below $-10 \mathrm{~dB}$ for Ha ranging from $15.62 \mathrm{~mm}$ to $15.96 \mathrm{~mm}$. In addition to that, Figure 22 shows that the real part of the proposed antenna's input impedance behaves similarly with good impedance matching defined by an input impedance close to $53 \Omega$ at $x=-7.5 \mathrm{~cm}, y=5 \mathrm{~cm}$, and $\mathrm{Ha}=16.8 \mathrm{~mm}$. Figure 23 depicts VSWR as functions of displacement of proposed CPW-Fed slot antennas along the $\mathrm{X}$-axis, $\mathrm{Y}$-axis, and Z-axis. It proves that the proposed full satellite achieves the lowest VSWR of 1.16 on the same antenna position, i.e., $\mathrm{x}=-7.5 \mathrm{~cm}$, $\mathrm{y}=5 \mathrm{~cm}$, and $\mathrm{Ha}=16.8 \mathrm{~mm}$. 


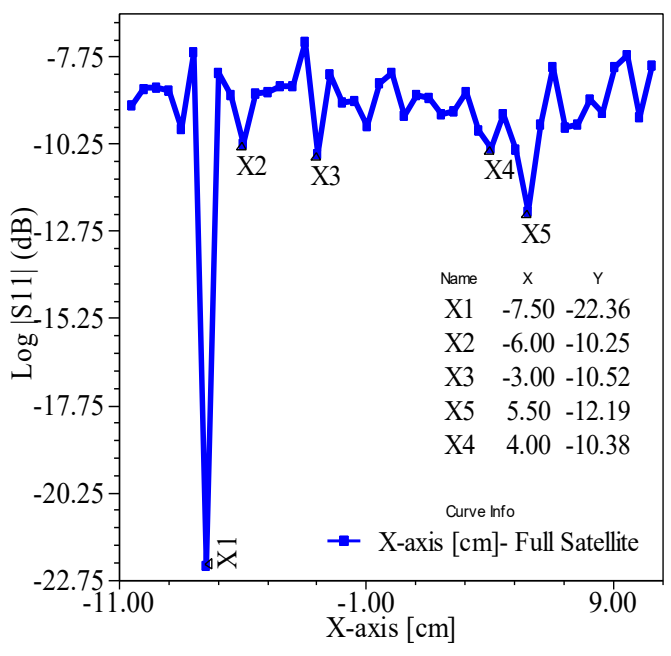

(a)

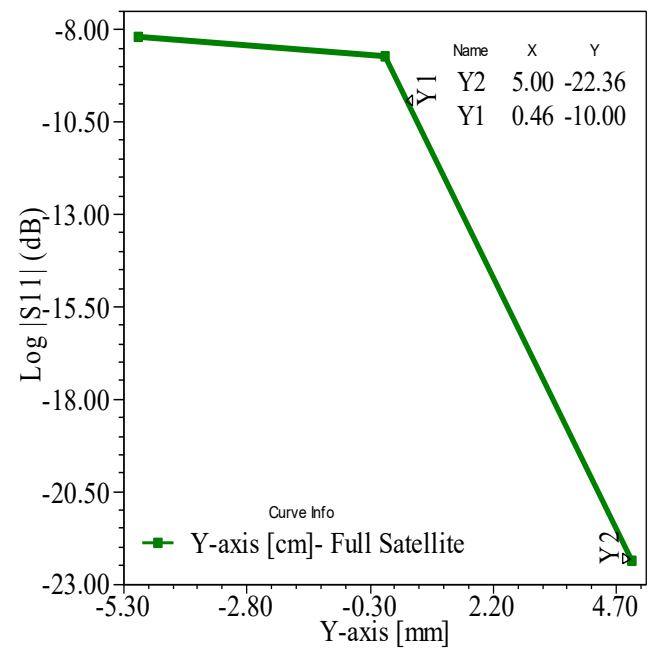

(b)

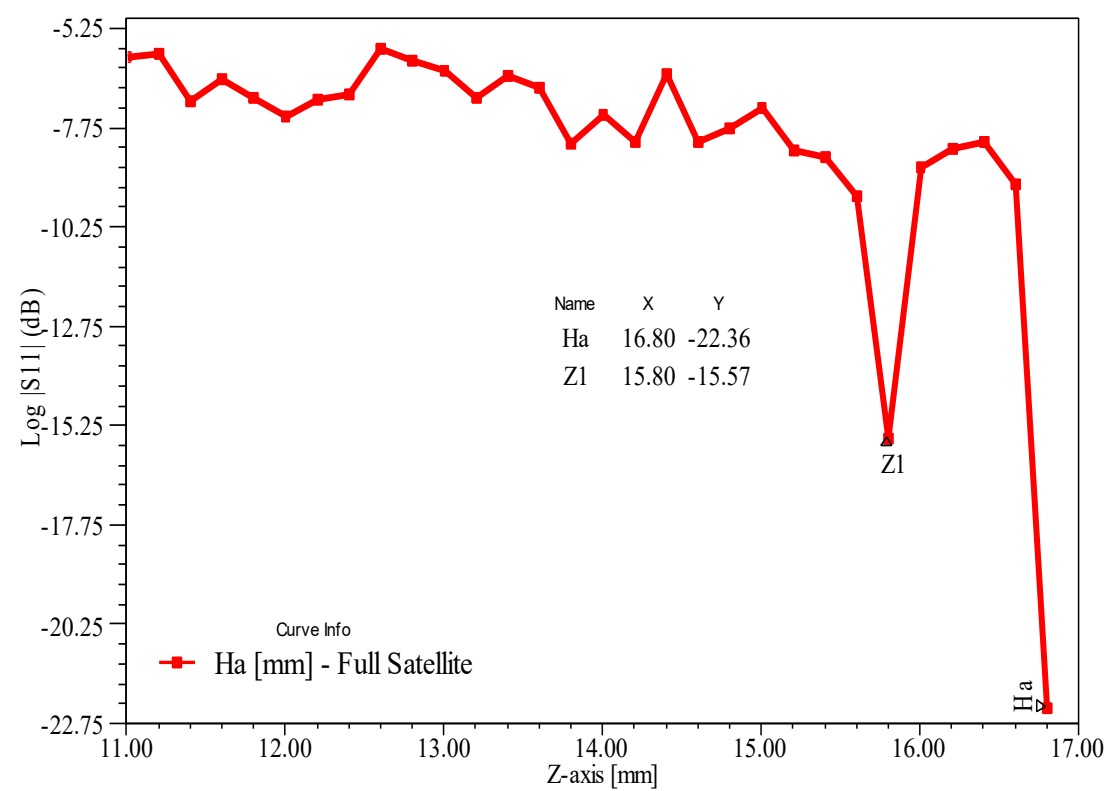

(c)

Figure 21. Reflection coefficient of the proposed full satellite at $2450 \mathrm{MHz}$ : Proposed antenna + 3U CubeSat: (a): Reflection coefficient versus X-axis; (b): Reflection coefficient versus Y-axis; (c): Reflection coefficient versus Z-axis.

The proposed full satellite achieves high return loss of about $23 \mathrm{~dB}$, VSWR close to one, and good impedance matching at $2450 \mathrm{MHz}$ for $\mathrm{x}=-7.5 \mathrm{~cm}, \mathrm{y}=5 \mathrm{~cm}$, and $\mathrm{Ha}=$ $16.8 \mathrm{~mm}$, which are optimized in this antenna design using the QNM optimization program introduced by Appendix C. Therefore, at this antenna position, the aluminum chassis of the $3 \mathrm{U}$ CubeSat body forwards back-lobe radiations generated by the proposed CPW-Fed slot antenna and then leads to maximizing radiating energy in the boresight direction at our ISM operating frequency of $2450 \mathrm{MHz}$. Consequently, that will minimize to the maximum interferences with other subsystems inside the CubeSat body from one side and permit our CubeSat communication system to cover larger orbits. Figure 24 shows that our CubeSat mission's obtained benefit is proved with a high gain of $8.19 \mathrm{dBi}$, total directivity of $8.4 \mathrm{dBi}$, and unidirectional radiation pattern at $2450 \mathrm{MHz}$. In addition to that, the proposed full satellite covers a large beamwidth of about $150^{\circ}$, and so wide coverage is accessible to our CubeSat mission at an ISM operating frequency. Table 5 summarizes the achieved results as per antenna position on the CubeSat body. 


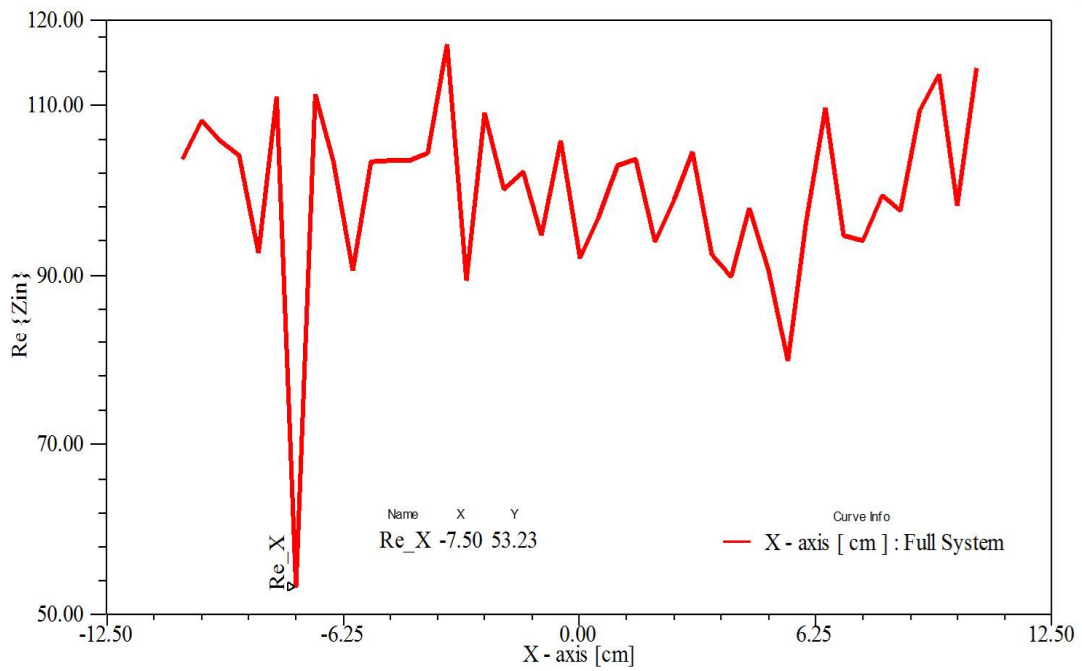

(a)

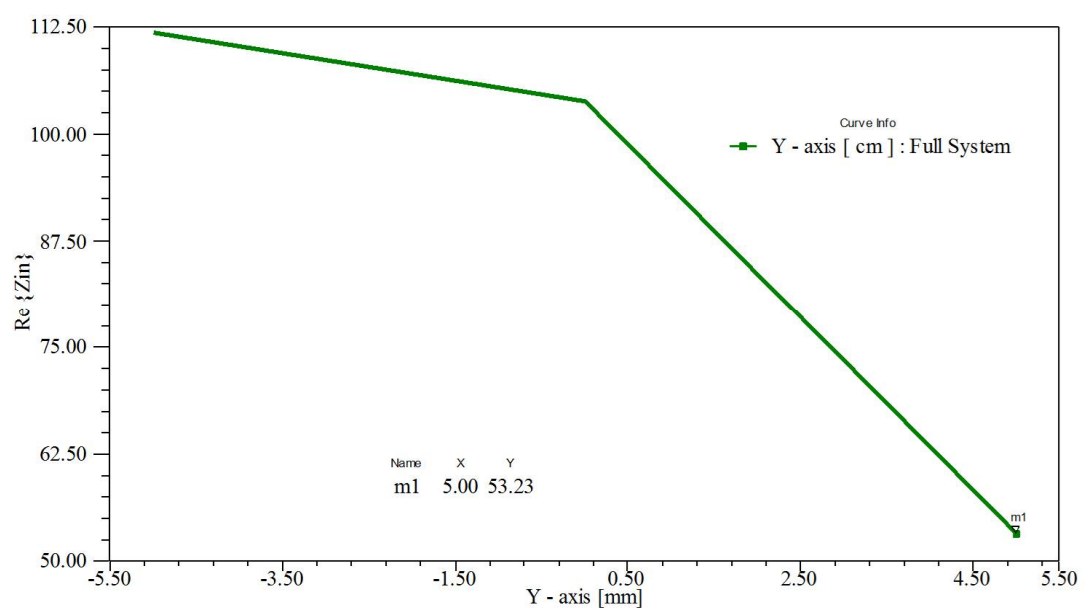

(b)

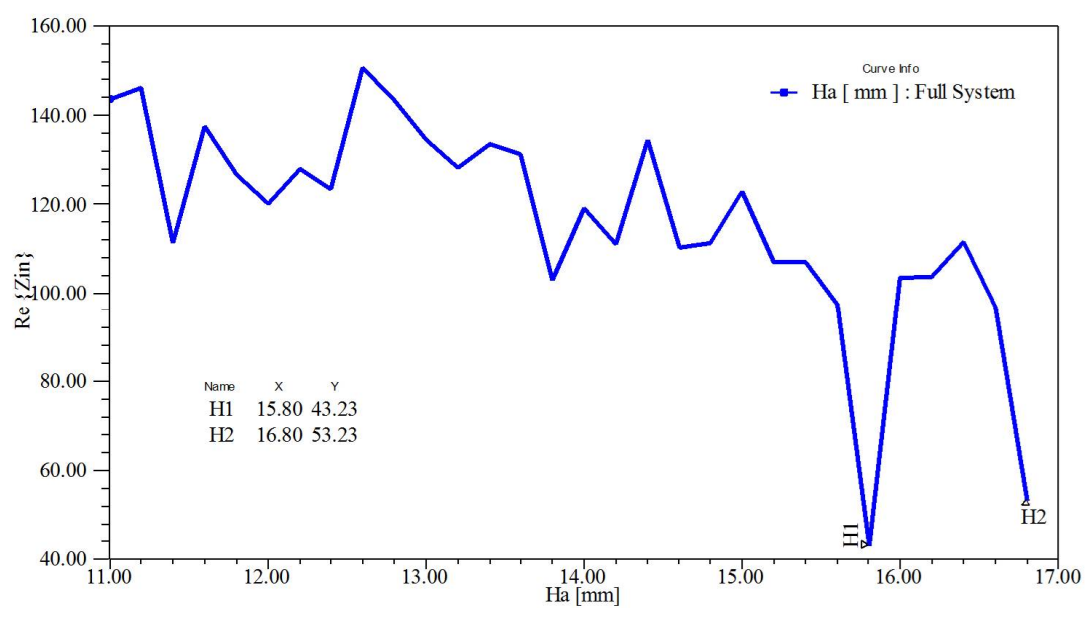

(c)

Figure 22. Input impedance real part of proposed full satellite at $2450 \mathrm{MHz}$ : Proposed antenna $+3 \mathrm{U}$ CubeSat: (a) Input impedance real part at $2450 \mathrm{MHz}$ versus X-axis (cm); (b) Input impedance real part at $2450 \mathrm{MHz}$ versus Y-axis (cm); (c) Input impedance real part at $2450 \mathrm{MHz}$ versus Z-axis (mm): $\mathrm{Ha}(\mathrm{mm})$. 


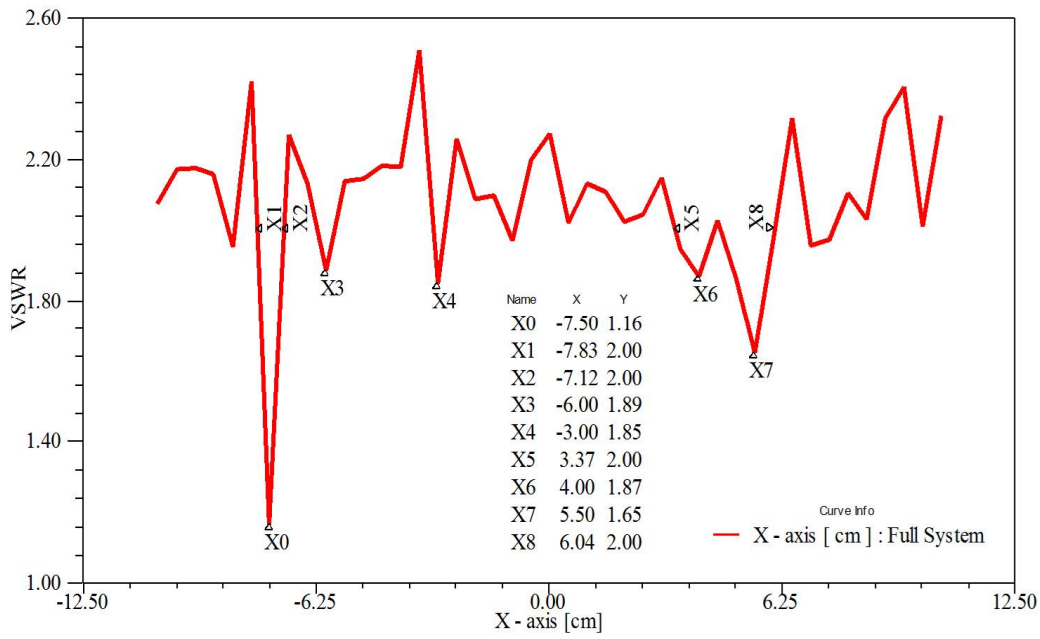

(a)

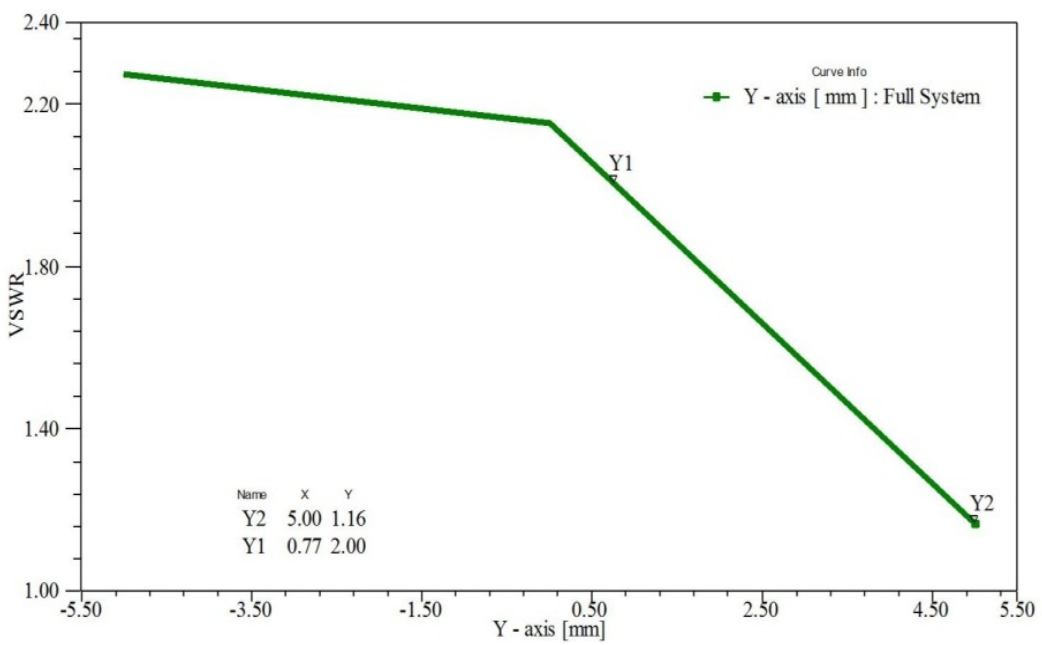

(b)

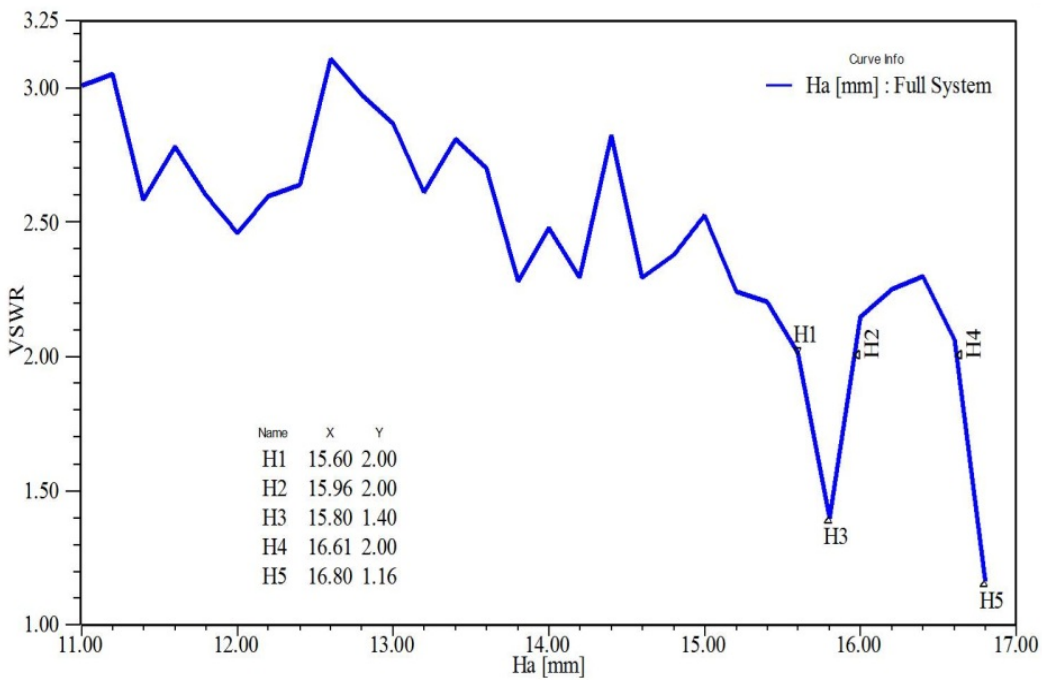

(c)

Figure 23. VSWR of proposed full satellite at $2450 \mathrm{MHz}$ : Proposed antenna + 3U CubeSat: (a) VSWR at $2450 \mathrm{MHz}$ versus Z-axis (mm): $\mathrm{Ha}(\mathrm{mm}) ;(\mathbf{b})$ : VSWR at $2450 \mathrm{MHz}$ versus Y-axis (cm); (c): VSWR at $2450 \mathrm{MHz}$ versus $\mathrm{Z}$-axis $(\mathrm{mm}): \mathrm{Ha}(\mathrm{mm})$. 


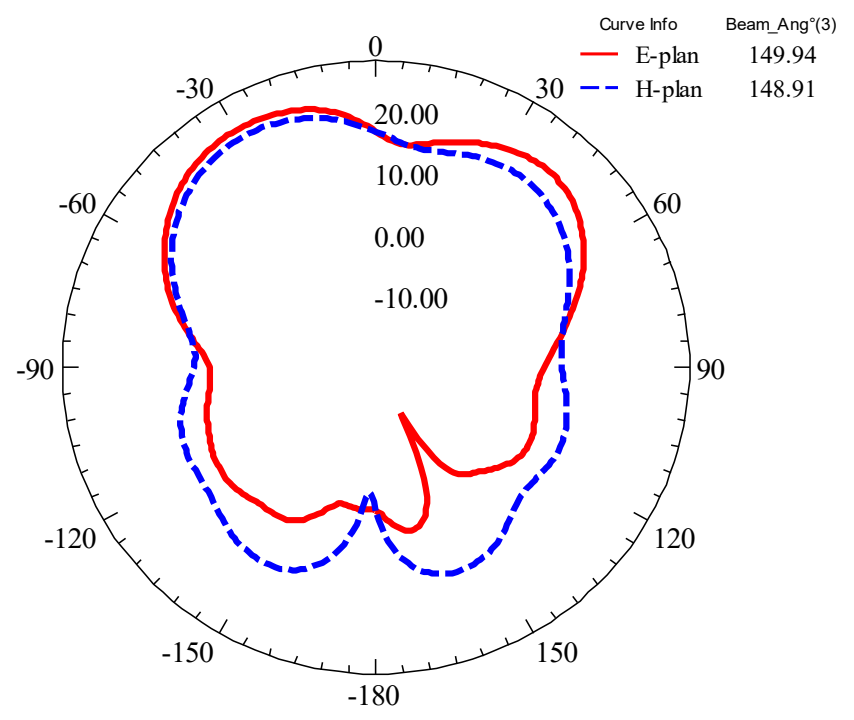

(a)
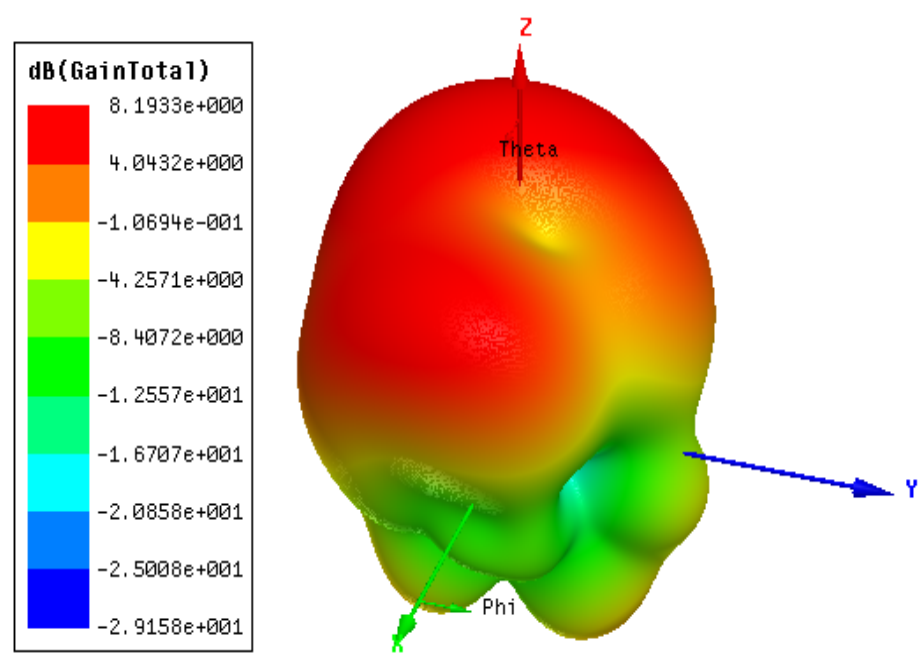

(b)
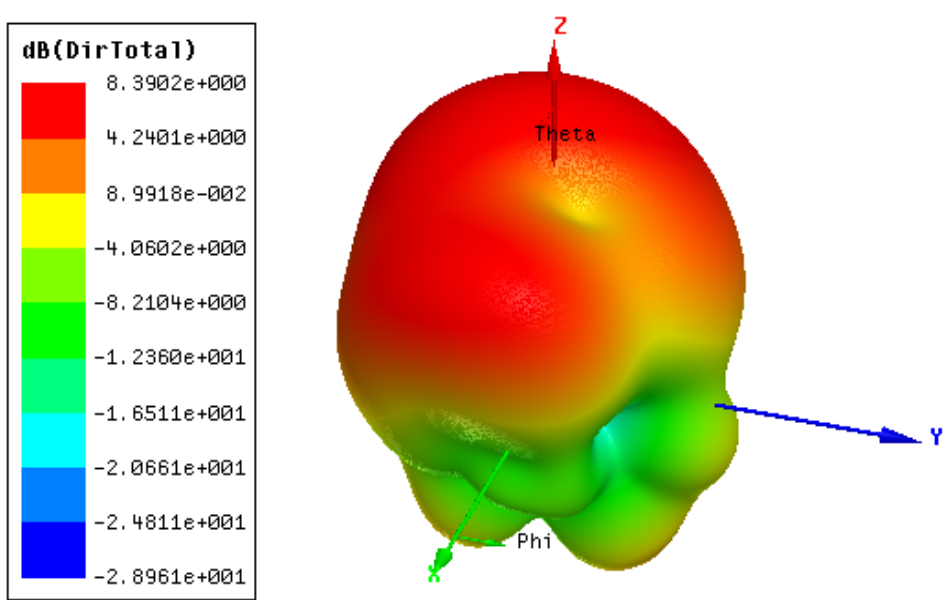

(c)

Figure 24. 2D radiation pattern, 3D gain, and total directivity of proposed full satellite at $2450 \mathrm{MHz}$ : (a) E- and H-fields at $2450 \mathrm{MHz}$ : phi $=0^{\circ} ; 90^{\circ}$; (b) 3D gain at $2450 \mathrm{MHz}$; (c) 3D directivity at $2450 \mathrm{MHz}$. 
Table 5. Performances of proposed full satellite at $2450 \mathrm{MHz}$ along $\mathrm{X}_{-}, \mathrm{Y}_{-}$, and Z-axis.

\begin{tabular}{|c|c|c|c|}
\hline Antenna Performances & X-Axis & Y-Axis & Z-Axis \\
\hline $\log |\mathrm{S} 11|<-10 \mathrm{~dB}$ & $\begin{array}{c}-7.5 \mathrm{~cm} ;-6 \mathrm{~cm} ;-3 \mathrm{~cm} \\
5.5 \mathrm{~cm} ; 4 \mathrm{~cm}\end{array}$ & $0.46 \mathrm{~mm}$ to $5 \mathrm{~mm}$ & $\begin{array}{l}15 \mathrm{~mm} \text { to } 16 \mathrm{~mm} ; 16.5 \mathrm{~mm} \text { to } \\
17 \mathrm{~mm}\end{array}$ \\
\hline VSWR $<2$ & $\begin{array}{c}-7.83 \mathrm{~cm} \text { to }-7.12 \mathrm{~cm} ;-6 \mathrm{~cm} \\
-3 \mathrm{~cm} ; 3.37 \mathrm{~cm} \text { to } 6.04 \mathrm{~cm}\end{array}$ & $0.77 \mathrm{~mm}$ to $5 \mathrm{~mm}$ & $\begin{array}{l}15.6 \mathrm{~mm} \text { to } 15.96 \mathrm{~mm} ; \\
16.61 \mathrm{~mm} \text { to } 17 \mathrm{~mm}\end{array}$ \\
\hline $\operatorname{Re}(\operatorname{Zin}) \sim 50 \Omega$ & $-7.5 \mathrm{~cm} ; 5.5 \mathrm{~cm}$ & $2.5 \mathrm{~mm}$ to $5 \mathrm{~mm}$ & $\begin{array}{c}15.7 \mathrm{~mm} \text { to } 15.9 \mathrm{~mm} ; 16.7 \mathrm{~mm} \\
\text { to } 17 \mathrm{~mm}\end{array}$ \\
\hline Optimal Solution & $\begin{array}{c}X=-7.5 \mathrm{~cm}: \\
\log |\mathrm{S} 11|=-22.36 \mathrm{~dB} \\
\operatorname{VSWR}=1.16 \\
\operatorname{Re}(\text { Zin })=53.23 \Omega \\
\text { Gain }=8.2 \mathrm{dBi} \\
\text { Directivity }=8.4 \mathrm{dBi} \\
\text { Unidirectional RP } \\
\text { Beamwidth }=150^{\circ} \\
\text { Efficiency } \sim 97 \%\end{array}$ & $\begin{array}{c}Y=5 \mathrm{~mm}: \\
\log |\mathrm{S} 11|=-22.36 \mathrm{~dB} \\
\mathrm{VSWR}=1.16 \\
\operatorname{Re}(\mathrm{Zin})=53.23 \Omega \\
\text { Gain }=8.2 \mathrm{dBi} \\
\text { Directivity }=8.4 \mathrm{dBi} \\
\text { Unidirectional RP } \\
\text { Beamwidth }=150^{\circ} \\
\text { Efficiency } \sim 97 \%\end{array}$ & $\begin{array}{c}\mathrm{Z}=16.8 \mathrm{~mm}: \\
\log |\mathrm{S} 11|=-22.36 \mathrm{~dB} \\
\mathrm{VSWR}=1.16 \\
\operatorname{Re}(\mathrm{Zin})=53.23 \Omega \\
\text { Gain }=8.2 \mathrm{dBi} \\
\text { Directivity }=8.4 \mathrm{dBi} \\
\text { Unidirectional RP } \\
\text { Beamwidth }=150^{\circ} \\
\text { Efficiency } \sim 97 \%\end{array}$ \\
\hline
\end{tabular}
coverage; very high efficiency

It is important to mention that an antenna for CubeSats can have different orientations on the CubeSat's body. In addition to that, one antenna is enough for CubeSat-Earth communication links because the antenna orientation can be ensured using magnetic torqueing from ground stations [19]. At the same time, one antenna per face is required for inter-CubeSat communications.

\section{Result Synthesis and Discussion}

Table 6 below summarizes antenna performances achieved by the proposed study in this research work where our CubeSat mission frequency was centered in $2450 \mathrm{MHz}$, and the S-matrix was normalized to $50 \Omega$. The proposed CPW-Fed slot antenna's reflection coefficient with and without CubeSat chassis is well below $-22 \mathrm{~dB}$ at our operating frequency of $2450 \mathrm{MHz}$, and the antenna operates on an ultra-wide band ranging from 2210 to $2900 \mathrm{MHz}(-10 \mathrm{~dB} \mathrm{BW}=690 \mathrm{MHz})$. Input impedance of CPW-Fed slot antenna alone is $49.97+\mathrm{j} 0.27 \Omega$ at $2450 \mathrm{MHz}$. Therefore, the real part is almost $50 \Omega$ with negligible imaginary part (very small value), which means good impedance matching is achieved, and then the maximum power is radiated into space. The slot antenna alone (design without CubeSat chassis) presents a bidirectional radiation pattern despite its high gain of $6.17 \mathrm{~dB}$ at $2450 \mathrm{MHz}$. This radiation mechanism is undesirable for CubeSat applications because it causes interferences with the electronic instruments inside the CubeSat box.

Moreover, the CubeSat body is used as a reflector to suppress back-lobe radiation and improve the antenna peak gain at our working frequency of $2450 \mathrm{MHz}$. Using a small part of the CubeSat's top face as a reflector is applied to achieve a unidirectional radiation pattern by redirecting the back-lobe radiation and consequently improving the peak gain of 8.17 at $2450 \mathrm{MHz}$. Consequently, the proposed antenna approach demonstrates that slot antennas can achieve higher gains at S-Band with high return loss (small reflection coefficient), wide impedance bandwidth ( $-10 \mathrm{~dB}$ BW), and good impedance matching around our CubeSat targeting frequency of $2450 \mathrm{MHz}$. These results and remarks are concluded in Table 6 below. 
Table 6. Brief summary of antenna performances of all proposed antenna designs.

\begin{tabular}{|c|c|c|c|c|c|}
\hline Proprieties & Antenna 1 & Antenna 2 & Antenna 3 & Antenna 4 & Full Satellite \\
\hline Full area & $\begin{array}{l}90 \mathrm{~mm} \times \\
90 \mathrm{~mm}\end{array}$ & $\begin{array}{c}90 \mathrm{~mm} \times \\
90 \mathrm{~mm}\end{array}$ & $90 \mathrm{~mm} \times 90 \mathrm{~mm}$ & $\begin{array}{c}90 \mathrm{~mm} \times \\
90 \mathrm{~mm}\end{array}$ & $\begin{array}{c}90 \mathrm{~mm} \times \\
90 \mathrm{~mm}\end{array}$ \\
\hline Feeding System & $50 \Omega$ strip line & $50 \Omega$ strip line & $50 \Omega$ CPW Fed line & $\begin{array}{c}50 \Omega \text { CPW Fed } \\
\text { line }\end{array}$ & $\begin{array}{c}50 \Omega \text { CPW Fed } \\
\text { line }\end{array}$ \\
\hline $\begin{array}{l}\text { Operating } \\
\text { Frequency }\end{array}$ & $2450 \mathrm{MHz}$ & $2450 \mathrm{MHz}$ & $2580 \mathrm{MHz}$ & $2450 \mathrm{MHz}$ & $2450 \mathrm{MHz}$ \\
\hline $\log |\mathrm{S} 11|$ & $-9.87 \mathrm{Db}$ & $-12.16 \mathrm{~dB}$ & $-18.39 \mathrm{~dB}$ & $-51.39 \mathrm{~dB}$ & $-22.36 \mathrm{~dB}$ \\
\hline VSWR & 1.95 & 1.65 & 1.27 & 1.01 & 1.16 \\
\hline $\operatorname{Re}(Z i n)$ & $92.23 \Omega$ & & $\sim 50 \Omega$ & $\sim 50 \Omega$ & $\sim 53 \Omega$ \\
\hline Gain & - & - & $\sim 6.2 \mathrm{dBi}$ & $\sim 6.2 \mathrm{dBi}$ & $8.20 \mathrm{dBi}$ \\
\hline $\mathrm{RP}$ & Bidirectional & Bidirectional & Bidirectional & Bidirectional & Unidirectional \\
\hline $\begin{array}{l}\text { Reflected } \\
\text { power }\end{array}$ & $\sqrt{ }$ & $\sqrt{ }$ & $\sqrt{ }$ & $\times$ & $\times$ \\
\hline Back lobes & $\sqrt{ }$ & $\sqrt{ }$ & $\sqrt{ }$ & $\sqrt{ }$ & $\times$ \\
\hline Advantages & $\begin{array}{l}\text { Lightweight, } \\
\text { low-cost, size } \\
\text { suitable for all } \\
\text { CubeSat } \\
\text { configurations }\end{array}$ & $\begin{array}{l}\text { Lightweight, } \\
\text { low-cost, size } \\
\text { suitable for all } \\
\text { CubeSat } \\
\text { configurations }\end{array}$ & $\begin{array}{l}\text { Lightweight, low-cost, size suitable } \\
\text { for all CubeSat configurations; } \\
\text { acceptable gain }\end{array}$ & $\begin{array}{l}\text { Lightweight, } \\
\text { low-cost, size } \\
\text { suitable for all } \\
\text { CubeSat } \\
\text { configurations; } \\
\text { acceptable gain; } \\
\text { good } \\
\text { impedance } \\
\text { matching }\end{array}$ & $\begin{array}{l}\text { Lightweight; } \\
\text { low-cost; size } \\
\text { suitable for all } \\
\text { CubeSat } \\
\text { configurations; } \\
\text { high gain; good } \\
\text { impedance } \\
\text { matching; } \\
\text { unidirectional } \\
\text { radiations }\end{array}$ \\
\hline Drawbacks & $\begin{array}{l}\text { Power losses } \\
\quad \text { and } \\
\text { interferences }\end{array}$ & $\begin{array}{l}\text { Power losses } \\
\quad \text { and } \\
\text { interferences }\end{array}$ & Power losses and interferences & Interferences & $\times$ \\
\hline Suggestions & $\begin{array}{l}\text { Notches; } \\
\text { CPW-Feed line; } \\
\text { Cavity reflector }\end{array}$ & $\begin{array}{l}\text { Notches; } \\
\text { CPW-Feed line; } \\
\text { Cavity reflector }\end{array}$ & Notches; Cavity reflector & Cavity reflector & $\sqrt{ }$ \\
\hline
\end{tabular}

It is also important to mention that the first two antenna parameters that verify the effectiveness of any CubeSat antenna are its full size and the peak gain at the target working frequency. Therefore, the antenna design that achieves the biggest gain can be preferred for use on CubeSats if its physical size is suitable with the desired CubeSat structure and the other antenna performances are acceptable for space missions at LEO. Henceforth, effectiveness of our equilateral triangular CPW-Fed slot antenna for $3 \mathrm{U}$ CubeSat missions is proved by its small size which is suitable for all CubeSat configurations and use of a simple CPW-Fed line that leads to low power consumption in exciting the antenna.

\section{Comparative Study: Brief Comparison with Literature Works}

A qualitative comparison between the proposed equilateral CPW-fed slot antenna and six S-band antenna designs with metasurface [20-31] is now provided; refer to Figure 25. We analyze, compare, and evaluate the suitability of all these antenna designs for 3U CubeSats using the following criteria: small physical size at S-band, wide impedance and Axial Ratio bandwidth, low reflection coefficient $(<-10 \mathrm{~dB})$, orientability, and high gain at S-band. We first present each antenna design approach and then examine their capabilities for uploading and downloading data at S-band using CubeSats. Lastly, we compare all antenna designs' suitability, including our equilateral triangular CPW-fed slot antenna for the $3 \mathrm{U}(10 \mathrm{~cm} \times 10 \mathrm{~cm} \times 30 \mathrm{~cm})$ CubeSat configuration. 


\subsection{Comparison with S-Band Metasurfaced/Metamaterial Antennas}

J. L. S. Paiva et al. proposed, in [20], the use of metasurface to enhance the peak gain at an S-band working frequency of $2460 \mathrm{MHz}$ and convert linear generated by an S-band microstrip antenna into circular polarization. The source antenna, which is a microstrip antenna, is printed on the dielectric Rogers Corporation RO4350, and an array of $4 \times 4$-unit cells, is used to configure the metasurface. This antenna design's key feature is a $45^{\circ}$ chamfered square ring shape in the upper left and lower right corners of each unit cell for converting the linear polarization (LP) generated by the source antenna to circular polarization (CP) at S-band. The metasurfaced antenna, then, generates a greater concentration of fields in the inter-unit cells spaces. It emits electric fields intensely in its horizontal directions in phases $0^{\circ}$ and $180^{\circ}$. In phases $90^{\circ}$ and $270^{\circ}$, the antenna emits principally electric fields in the metasurface's vertical directions. These horizontal and vertical distributions of fields through the metasurface unit cells take turn to generate $\mathrm{CP}$ signal by emitting horizontal and vertical signals.

This metasurfaced antenna generates $C P$ with an AR close to $0 \mathrm{~dB}, \mathrm{ARBW}$ of $113 \mathrm{MHz}$, and $5.69 \mathrm{dBi}$ at the target working frequency of $2460 \mathrm{MHz}$. Because these results are suitable for CubeSat missions at orbits close to the earth surface, this metasurfaced antenna design can be used for CubeSats at very low orbits and inter-CubeSat communications despite its high volume on the CubeSat body. Whereas, iplinking and downlinking of data at deep orbits using CubeSats require higher values of gains at $2460 \mathrm{MHz}$.

In [21], S. Chaimool et al. used PIN diodes for reconfiguring metasurface for dual operations when the diode is forward-prejudiced or reverse-prejudiced. Hence, the metasurface presents the characteristics of epsilon-negative materials and then reflects all incident radiation with an appropriate polarization when the PIN diode is forward-prejudiced at the frequency of interest. Whereas, it presents characteristics of mu-near-zero materials and then directs radiation when the diode is reverse-prejudiced. Because of these two controllable metasurface behaviors, a controlled feeding dipole is proposed for the use of beam switching in opposite regions at the same frequency of interest in order to control radiation patterns of the proposed metasurfaced antenna using bias of PIN diodes and so ensure the maximum gain. Therefore, the electromagnetic coupling between unit cells and feeding dipole shifts the dipole's lower frequencies when PIN diodes of the metasurface are forward-prejudiced. So, a reverse favor voltage is applied to the dipole PIN diodes to ensure higher frequencies. However, the dipole shifts higher frequencies when PIN diodes of the metasurface are reverse-prejudiced. A forward prejudice voltage is applied to the dipole PIN diodes to ensure the target operating frequency of $2450 \mathrm{MHz}$. Hence, the metasurface works as a reflector when diodes of both metasurface and the feeding dipole are forward- and reverse-prejudiced, respectively; and acts as a director when the metasurface and dipole diodes are reverse- and forward-prejudiced, respectively.

This metasurfaced antenna achieves good impedance matching for both diode states, gives maximum gain of about $6 \mathrm{dBi}$ at $2450 \mathrm{MHz}$, while its high volume, cost, and electric controllability using PIN diodes limit its effectiveness for use on CubeSats.

In [22], A. H. Naqvi et al. proposed an S-band microfluidic slotted antenna with metasurface. The source antenna is an LP simple slotted patch antenna that generates a metasurface of $4 \times 4$ microfluidic unit cells. In this antenna design, LP signal is converted to left-hand circular polarization (LHCP) and right-hand circular polarization (RHCP) signal through the metasurface, which is bonded with microfluidic channel layers. The proposed microfluidic antenna achieves a $3 \mathrm{~dB}$ axial ratio bandwidth from $2.47 \mathrm{GHz}$ to $2.55 \mathrm{GHz}$ for the LHCP and from $2.49 \mathrm{GHz}$ to $2.55 \mathrm{GHz}$ for the RHCP, with peak gains of $5.86 \mathrm{dBi}$ and $5.84 \mathrm{dBi}$ at $2510 \mathrm{MHz}$ in boresight for LHCP and RHCP, respectively. Therefore, this microfluidic polarization-switchable antenna presents good ARBW and acceptable gains for use at CubeSat orbits close to the Earth's surface. However, high volume and the use of three dielectric materials limit this antenna configuration's effectiveness for transmitting data between CubeSats at deep orbits and Earth stations. 


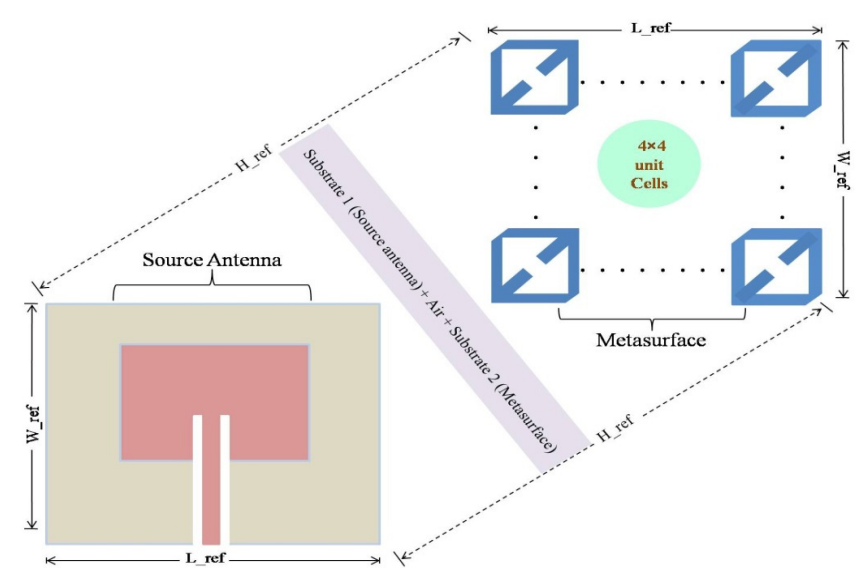

(a)

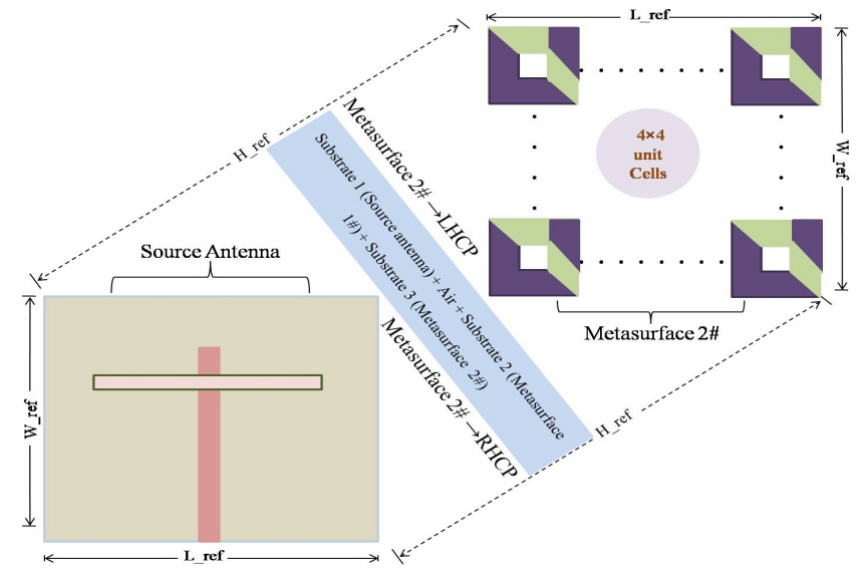

(c)

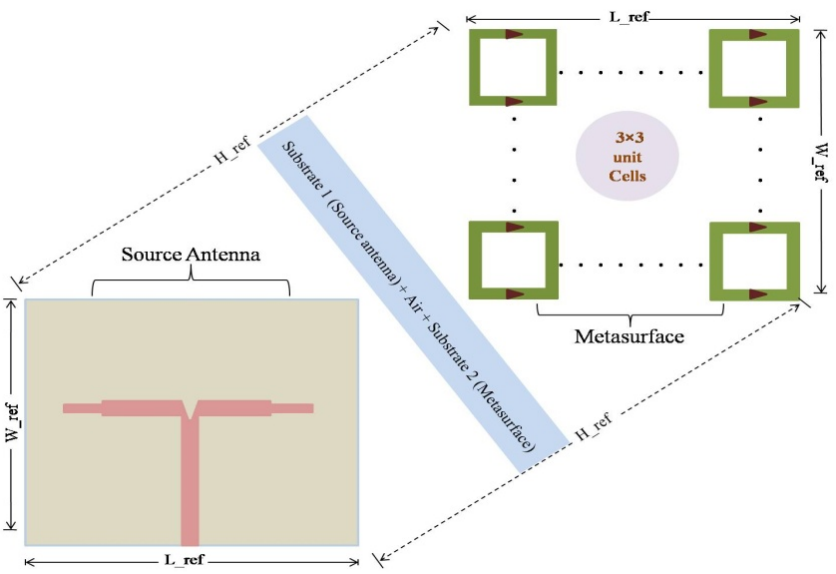

(b)

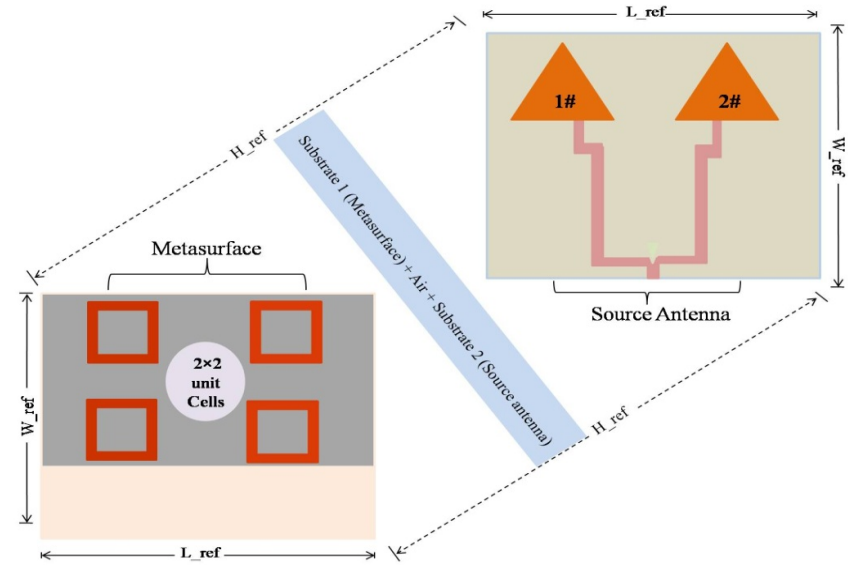

(d)

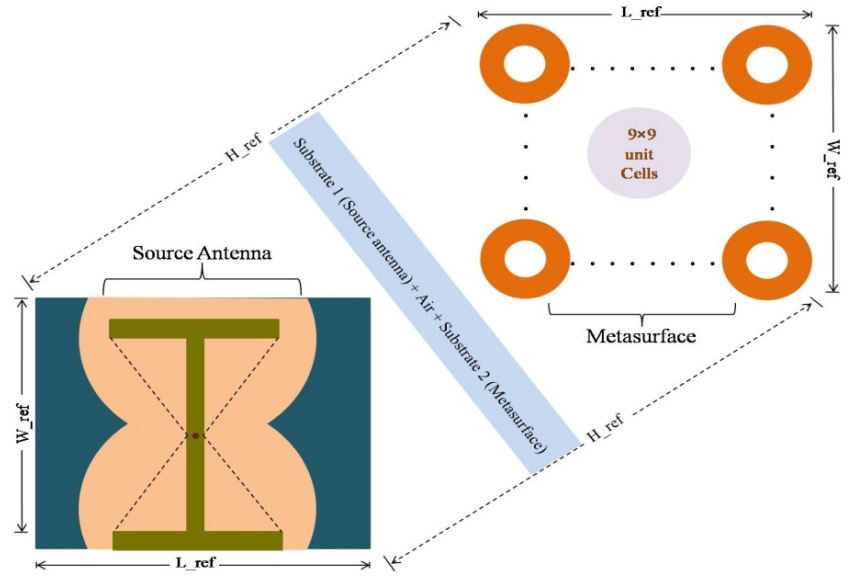

(e)

Figure 25. Candidate antennas with metasurface for CubeSats [20-24]: (a) S-band microstrip patch antenna with metasurface [20]; (b) Controlled reconfigurable S-band antenna with metasurface [21]; (c) Microfluidic slotted patch antenna with metasurface [22]; (d) CP Reconfigurable monopole antenna with metasurface [23]; (e) S-band slot antenna with metasurface [24].

In [23], Y.F. Cao proposed an S-band monopole antenna with metasurface for use at S-band. The proposed antenna consists of two monopoles, a switchable feeding network, and a metasurface. The dual-cap mushroom-like unit cells are proposed for improving the $-10 \mathrm{~dB}$ bandwidth with small size. The two monopoles are used for achieving $-10 \mathrm{~dB}$ bandwidth and good impedance matching at $1580 \mathrm{MHz}$. The metasurface enhances the peak gain from 0.4 to $6.6 \mathrm{dBi}$, and the impedance bandwidth from $330 \mathrm{MHz}$ to $460 \mathrm{MHz}$, 
respectively. Therefore, this reconfigurable metasurfaced antenna presents acceptable results for use on CubeSats at orbits close to the Earth's surface. Its high volume, complexity of structure, controllability, and medium gain limit a CubeSat mission's success using this antenna in the space environment.

In [24], M. El Bakkali et al. proposed an S-band slot antenna with metasurface for use on CubeSats. This antenna design consists of a miniaturized slot antenna and an MSS of a $7 \times 7$ matrix of unit cells placed atop the first one. The used metasurface enhances the $-10 \mathrm{~dB}$ bandwidth and total gain from $93.72 \mathrm{MHz}$ to $261.47 \mathrm{MHz}$, and $3.07 \mathrm{dBi}$ to $5.4 \mathrm{dBi}$, respectively. This Metasurface Superstrate Structure (MSS) antenna is low-profile and occupies a physical size suitable for all CubeSat configurations, while the use of two dielectric materials increases its cost and weight on the CubeSat body. In addition to that, the medium gain achieved by this antenna design cannot ensure deep orbits.

Table 7 summarizes the design properties and radiation characteristics of this qualitative comparison. It shows that our equilateral triangular CPW-Fed slot antenna achieves the highest gain at S-band and presents the lowest volume and cost.

Table 7. A brief comparison with literature works on S-band metasurface/metamaterial antennas.

\begin{tabular}{ccccccc}
\hline Reference & Frequency & $\begin{array}{c}\text { Dielectric } \\
\text { mat. }\end{array}$ & $\begin{array}{c}\text { Feeding } \\
\text { Syst. }\end{array}$ & Volume/Size & Gain & CubeSat \\
\hline$[20]$ & $2460 \mathrm{MHz}$ & $\begin{array}{c}\text { Rogers } \\
\text { RO4350 }\end{array}$ & $\begin{array}{c}\text { Microstrip } \\
\text { line }\end{array}$ & $\begin{array}{c}96.5 \times 96.5 \\
\times 20 \mathrm{~mm}^{3}\end{array}$ & $5.69 \mathrm{dBi}$ & $3 \mathrm{U}$ \\
\hline$[21]$ & $2450 \mathrm{MHz}$ & FR-4 & $\begin{array}{c}\text { Controlled } \\
\text { dipole }\end{array}$ & $\begin{array}{c}80 \times 80 \times \\
11 \mathrm{~mm}^{3}\end{array}$ & $\sim 6.0 \mathrm{dBi}$ & $6 \mathrm{U}$ \\
\hline$[22]$ & $2510 \mathrm{MHz}$ & $\begin{array}{c}\text { Rogers } \\
3003\end{array}$ & $\begin{array}{c}\text { microfluid } \\
\text { injection }\end{array}$ & $\begin{array}{c}120 \times 120 \\
\times 21 \mathrm{~mm}^{3}\end{array}$ & $5.86 \mathrm{dBi}$ & $6 \mathrm{U}$ \\
\hline$[23]$ & $1580 \mathrm{MHz}$ & $\begin{array}{c}\text { Rogers } \\
3003\end{array}$ & $\begin{array}{c}\text { Phase } \\
\text { shifters }\end{array}$ & $\begin{array}{c}71 \times 92 \times \\
20.4 \mathrm{~mm}^{3}\end{array}$ & $6.6 \mathrm{dBi}$ & $3 \mathrm{U}$ \\
\hline [24] & $2450 \mathrm{MHz}$ & FR-4 & $50 \Omega \mathrm{CPW}$ & $\begin{array}{c}54 \times 62 \times \\
10.4 \mathrm{~mm}^{3}\end{array}$ & $5.4 \mathrm{dBi}$ & $3 \mathrm{U}$ \\
\hline Our work & $2450 \mathrm{MHz}$ & FR-4 & $50 \Omega \mathrm{CPW}$ & $\begin{array}{c}90 \times 90 \times \\
1.6 \mathrm{~mm}^{3}\end{array}$ & $8.2 \mathrm{dBi}$ & $3 \mathrm{U}$ \\
\hline
\end{tabular}

\subsection{Comparison with S-Band Antenna Designs of Six International Collaborative CubeSat Missions}

In this subsection, the proposed antenna design is compared with planar antenna designs of six international collaborative CubeSat missions at UHF and S-bands. Table 8 shows that our CubeSat antenna gives the highest gain, low reflected power with suitability for all CubeSat configurations. Moreover, our antenna is low-cost, lightweight, and can be easily integrated with the other CubeSat Subsystems.

Through the previous analysis and data given in Tables 7 and 8, our equilateral triangular antenna presented in this paper is high-gain, lightweight, low-cost, and occupies physical size suitable for all CubeSat configurations, including the $3 \mathrm{U}$ structure. This CPW-SA, therefore, is the best among the cited designs in Table 6 and permits the CubeSat constructor to implement more solar panels on the CubeSat box for producing the maximum power possible. 
Table 8. Brief comparison with UHF- and S-bands planar antenna designs proposed by CubeSat missions.

\begin{tabular}{|c|c|c|c|c|c|c|c|}
\hline Reference & [25] & {$[26,27]$} & [28] & [29] & [30] & [31] & Our Work \\
\hline Country & $\begin{array}{l}\text { China } \\
\text { Japan }\end{array}$ & South Africa & Europe & USA & South Korea & Malaysia & Morocco \\
\hline Frequency & $2180 \mathrm{MHz}$ & $2420 \mathrm{MHz}$ & $2150 \mathrm{MHz}$ & $2250 \mathrm{MHz}$ & $\begin{array}{l}900 \mathrm{MHz} \\
2200 \mathrm{MHz}\end{array}$ & $450 \mathrm{MHz}$ & $2450 \mathrm{MHz}$ \\
\hline $\begin{array}{l}\text { Dielectric } \\
\text { mat. }\end{array}$ & $\begin{array}{c}(\varepsilon \mathrm{r}=2.17 \\
\tan \delta=0.005 \\
\mathrm{~h}=1.6 \mathrm{~mm}\end{array}$ & $\begin{array}{l}\text { Air (metal } \\
\text { antenna) }\end{array}$ & $\begin{array}{l}\text { Rogers } \\
\text { TMM4; } \\
\text { Rogers } \\
\text { RO4003 }\end{array}$ & - & $\begin{array}{c}\text { Paper } \\
\text { substrate }\end{array}$ & $\begin{array}{c}\text { Solar } \\
\text { panel/Air }\end{array}$ & FR-4 \\
\hline Feeding Syst. & $\begin{array}{l}\text { Microstrip } \\
\text { line }\end{array}$ & Coaxial Feed & Coaxial Feed & Coaxial Feed & $\begin{array}{l}\text { Microstrip } \\
\text { line }\end{array}$ & Coaxial Feed & $50-\Omega \mathrm{CPW}$ \\
\hline Volume/Size & $\begin{array}{c}100 \times 95 \times \\
1.6 \mathrm{~mm}^{3}\end{array}$ & $\begin{array}{c}\sim 100 \times 100 \\
\mathrm{~mm}^{2}\end{array}$ & $\begin{array}{l}66 \times 66 \times \\
25.5 \mathrm{~mm}^{3}\end{array}$ & $\begin{array}{c}82 \times 82 \times \\
12 \mathrm{~mm}^{3}\end{array}$ & $\begin{array}{c}50 \times 50 \times \\
50 \mathrm{~mm}^{3}\end{array}$ & $\begin{array}{c}80 \times 90 \times \\
0.5 \mathrm{~mm}^{3}\end{array}$ & $\begin{array}{c}90 \times 90 \times \\
1.6 \mathrm{~mm}^{3}\end{array}$ \\
\hline Gain & $4.66 \mathrm{dBic}$ & $\sim 7.0 \mathrm{dBi}$ & $\sim 7.0 \mathrm{dBi}$ & $\sim 7.0 \mathrm{dBi}$ & $\begin{array}{c}1.11 \mathrm{dBi} ; 2.32 \\
\mathrm{dBi}\end{array}$ & $0.6 \mathrm{dBi}$ & $8.2 \mathrm{dBi}$ \\
\hline $\log |S 11|$ & $<-50 \mathrm{~dB}$ & $<-15 \mathrm{~dB}$ & $\sim-7.0 \mathrm{~dB}$ & - & $\begin{array}{l}\sim-16 \mathrm{~dB} ; \\
\sim-18 \mathrm{~dB}\end{array}$ & $\sim-16 \mathrm{~dB}$ & $-22.36 \mathrm{~dB}$ \\
\hline $\begin{array}{c}\text { Solar } \\
\text { Integration } \\
\text { Facility }\end{array}$ & Yes & Yes & No & No & No & Yes & Yes \\
\hline Cost & Medium & High & High & Medium & Low & High & Low \\
\hline CubeSat & $3 \mathrm{U}$ & $3 \mathrm{U}$ & $3 \mathrm{U}$ & $3 \mathrm{U}$ & $3 U$ & $1 \mathrm{U} ; 2 \mathrm{U} ; 3 \mathrm{U}$ & $1 \mathrm{U} ; 2 \mathrm{U} ; 3 \mathrm{U}$ \\
\hline
\end{tabular}

\section{Conclusions}

A high-gain equilateral triangular slot antenna at an ISM operating frequency of $2450 \mathrm{MHz}$ is presented in this paper. This antenna design targets CubeSat communications at S-band and, specifically, the configuration of 3U. It was found that a high gain of $8.20 \mathrm{dBi}$ at $2450 \mathrm{MHz}$ is obtained using a metallic part of the CubeSat chassis below the slot antenna as a reflector. Moreover, the radiation pattern becomes unidirectional at the same operating frequency. The achieved results have shown that the constructed antenna achieves a return loss of about $23 \mathrm{~dB}$, input impedance close to $50 \Omega$ at $2450 \mathrm{MHz}$, and ultra-wide $-10 \mathrm{~dB}$ BW of $1240 \mathrm{MHz}(2230-3470 \mathrm{MHz})$. It is also important to note here that the constructed antenna design has a lightweight and compact size, which makes it suitable for any CubeSat structure.

Author Contributions: Conceptualization, M.E.B. (Mohamed El Bakkali) and M.E.B. (Moulhime El Bekkali); Methodology, M.E.B. (Mohamed El Bakkali) and M.E.B. (Moulhime El Bekkali); Formal analysis, M.E.B. (Mohamed El Bakkali), M.E.B. (Moulhime El Bekkali), and J.M.G.; Results interpretation, M.E.B. (Mohamed El Bakkali), M.E.B. (Moulhime El Bekkali), and J.M.G.; Writingoriginal draft preparation, M.E.B. (Mohamed El Bakkali), M.E.B. (Moulhime El Bekkali), and J.M.G.; Writing-review and editing, G.S.G., L.K., and M.M.; Supervision, M.E.B. (Mohamed El Bakkali), J.M.G., and M.M.; Project administration, G.S.G. and L.K.; Funding acquisition, M.M. All authors have read and agreed to the published version of the manuscript.

Funding: Taif University Researchers Supporting Project number (TURSP-2020/10), Taif University, Taif, Saudi Arabia.

Acknowledgments: We are grateful for the support from Taif University Researchers Supporting Project number (TURSP-2020/10), Taif University, Taif, Saudi Arabia. We also like to thank Faisel Tubbal, Son Xuat Ta, and Niamat Husein for their valuable support in investigating and providing us access to their scientific tool.

Conflicts of Interest: The authors declare no conflict of interest. 


\section{Appendix A. Moroccan CubeSat One (MaSat 1) of Sidi Mohamed Ben Abdellah University, City of Fez, Morocco}

Sidi Mohamed Ben Abdellah University has finished the development of its first nationally made CubeSat (MaSat 1). MaSat 1 weighs just $960 \mathrm{~g}$ and was manufactured by a group of students from the same university. University of Oujda and Al Akhawayn University in Ifrane also contributed to the project of MaSat 1 which was funded by the Ministry of Higher Education.

The first Moroccan-made satellite is a simple cube with a volume of 10 Cubic centimeters and mass of $960 \mathrm{~g}$. The cube-shaped satellite will have five faces covered with solar panels. The sixth face will carry the CubeSat antenna allowing transmission with two ground stations in Fez and Ifrane. MaSat 1 has a power of 1 watt, and a lifetime between 6 months and 2 years. It will also include a camera and will be at an altitude of $650 \mathrm{~km}$.

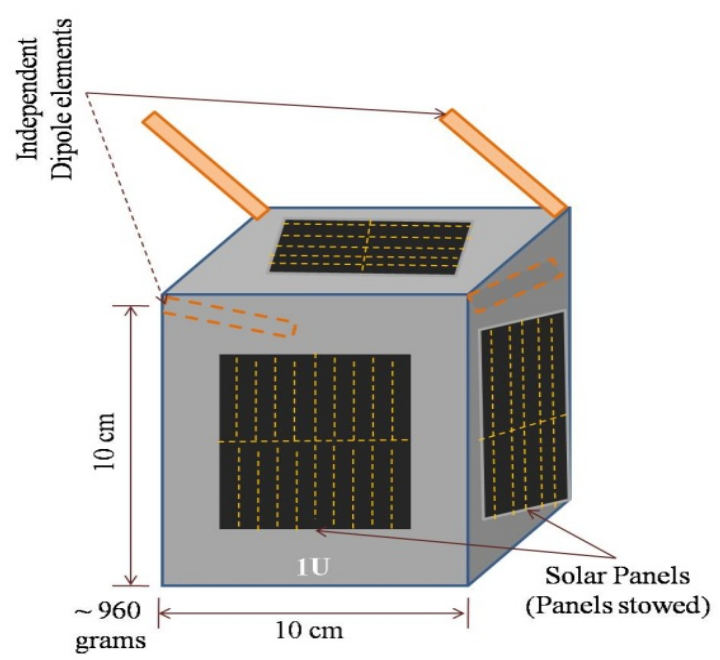

Figure A1. 3D model of MaSat 1: CubeSat of Sidi Mohamed Ben Abdellah University, city of Fez, Morocco [6].

Appendix B. List of Parameters Used in Designing the Proposed Antennas

Table A1. Antenna parameters used in designing the proposed antennas.

\begin{tabular}{|c|c|}
\hline Parameter & Behavior \\
\hline L1 & $\begin{array}{l}\text { Long distance between the antenna corner and the excitation } \\
\text { source }\end{array}$ \\
\hline W0 & Antenna physical width/antenna physical length \\
\hline $\mathrm{Lb}$ & $\begin{array}{l}\text { Diagonal distance between the antenna center and the } \\
\text { excitation source. }\end{array}$ \\
\hline Lc & Length of the CPW-fed line \\
\hline Wc & Width of the CPW-fed line \\
\hline Lf & Length of the transition line \\
\hline Wf & Width of the transition line \\
\hline $\mathrm{Ha}$ & $\begin{array}{l}\text { Air gap distance between the antenna dielectric and the } \\
\text { CubeSat chassis }\end{array}$ \\
\hline $\mathrm{D}, \mathrm{d} 0, \mathrm{~d} 1$, & Distances between the triangular edge and the ground plane \\
\hline $\operatorname{Rg}, \operatorname{Rg} 0, \operatorname{Rg} 1$ & Radius of the circular slot-ground plane \\
\hline $\mathrm{dg}, \operatorname{dg} 0, \operatorname{dg} 1$ & Distance between the CPW-Fed line and the ground plane \\
\hline$x$ & Antenna position along $\mathrm{X}$-axis \\
\hline $\mathrm{y}$ & Antenna position along Y-axis \\
\hline$x$ & Antenna position along Z-axis \\
\hline
\end{tabular}




\section{Appendix C. QNM Program}

In this research work, QNM is used to optimize antenna position on the CubeSat chassis for operation at $2450 \mathrm{MHz}$. In this optimization program, the proposed CPW-fed slot antenna is placed first on center of the CubeSat top face and then displacement along $\mathrm{X}_{-}, \mathrm{Y}-$, and $\mathrm{Z}$-axis is studied. The QNM program starts, therefore, with $\mathrm{x}=\mathrm{y}=0 \mathrm{~mm}$ and analyzes the full satellite performances at $2450 \mathrm{MHz}$. If the calculated RL and peak gain are greater than $20 \mathrm{~dB}$ and $8.0 \mathrm{dBi}$ at $2450 \mathrm{MHz}$ with an antenna placement suitable for our $3 \mathrm{U}$ CubeSat mission, the criteria are satisfied, and the optimization is terminated. Else, the results are not satisfied and then the optimization goes to the next triplet $(x ; y ; z)$ on the CubeSat tope face. The proposed QNM program is defined on 80 iterations per axis. This means that if the 80 iterations cannot satisfy the program criteria, the optimization problem is unsolved at $2450 \mathrm{MHz}$ using QNM.

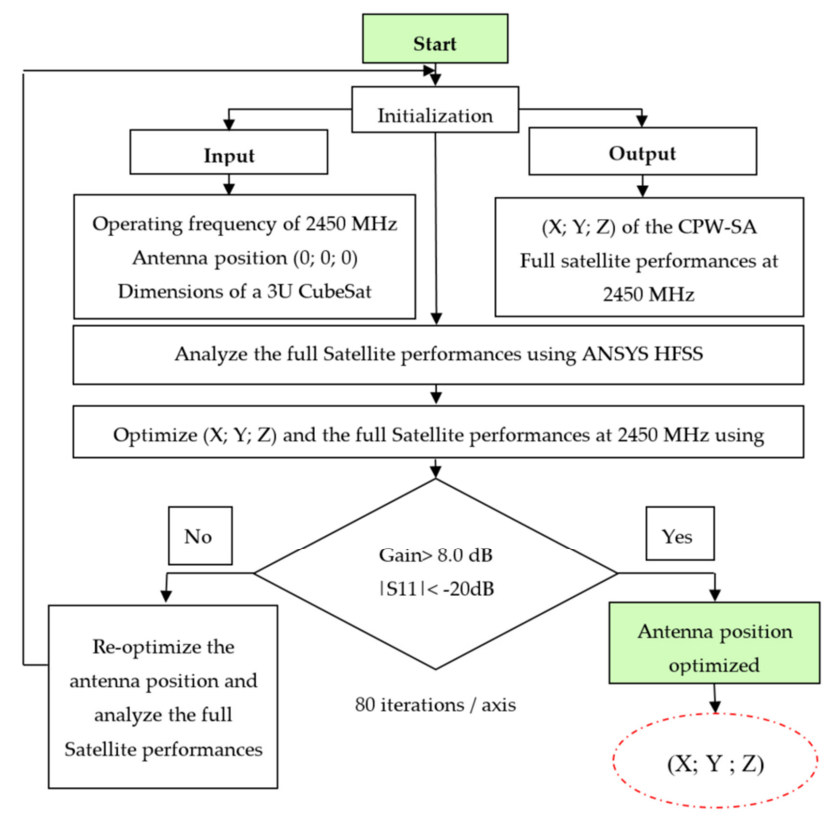

Figure A2. Flow chart of the QNM program used to optimize the antenna position.

In the present study, the proposed QNM scenario gives good solution of antenna placement at $2450 \mathrm{MHz}$ when for $\mathrm{x}=-7.5 \mathrm{~cm}, \mathrm{y}=5 \mathrm{~cm}$, and $\mathrm{Ha}=16.8 \mathrm{~mm}$. The antenna satisfied all proposed criteria, is high-gain, and occupies physical size suitable for all CubeSat configurations including $3 \mathrm{U}$ structure.

\section{References}

1. Valenzuela, A.; Sandau, R.; Roeser, H.-P. Small Satellite Missions for Earth Observation: New Developments and Trends; Springer Science \& Business media: Berlin/Heidelberg, Germany, 2010.

2. Tubbal, F.E.; Raad, R.; Chin, K.-W. A survey and study of planar antennas for pico-satellites. IEEE Access 2015, 3, 25902612. [CrossRef]

3. Rodríguez-Osorio, R.M.; Ramírez, E.F. A Hands-On Education Project: Antenna Design for Inter-CubeSat Communications [Education Column]. IEEE Antennas Propag. Mag. 2012, 54, 211-224. [CrossRef]

4. Swartwout, M. The First One Hundred CubeSats, A Statistical Look. JoSS 2013, 2, 213-233.

5. Shiroma, W.A.; Martin, L.K.; Akagi, J.M.; Akagi, J.T.; Wolfe, B.L.; Fewell, B.A. CubeSats: A bright future for nanosatellites. Cent. Eur. J. Eng. 2011, 1, 9-15. [CrossRef]

6. Dahbi, S.; Aziz, A.; Zouggar, S.; El hafyan, M.; Hanafi, A.; Karim, M.; Latachi, I.; Rachidi, T. Power Budget Analysis for a LEO polar orbiting Nano-satellite. In Proceedings of the 3rd International Conference on Advanced Technologies for Signal and Image Processing (ATSIP'2017), Fez, Morocco, 22-24 May 2017; pp. 1-6.

7. Suari, J.P.; Turner, C.; Ahlgren, W. Development of the standard CubeSat Deployer and a CubeSat class picosatellite. In Proceedings of the 2001 IEEE Aerospace Conference Proceedings (cat. No. 01TH8542), Big Sky, MT, USA, 11-17 March 2001; Volume 1, pp. 1347-1353. 
8. El Bakkali, M. Planar Antennas with Parasitic Elements and Metasurface Superstrate Structure for 3U CubeSats. Ph.D. Thesis, Sidi Mohamed Ben Abdellah University, Fez, Morocco, July 2020.

9. Tubbal, F.E.; Raad, R.; Chin, K.-W. A wideband F-shaped patch antenna for S-band CubeSats communications. In Proceedings of the 10th International Conference on Signal Processing and Communication Systems, ICSPCS 2016, Surfers Paradise, Australia, 19-21 December 2016.

10. Tabakh, I.; Jorio, M.; El Idrissi, N.E.A. MPA radiation characteristics evolution through a DGS size reduction study. In Proceedings of the 2016 International Conference on Wireless Networks and Mobile Communications, Fez, Morocco, 26-29 October 2016.

11. Tabakh, I.; Jorio, M.; El Idrissi, N.A. 1*2 RFID-Reader Array Antenna for Narrowband Indoor Positioning Applications. J. Eng. Sci. Technol. Rev. 2019, 12, 167-172. [CrossRef]

12. Chaimool, S.; Rakluea, C.; Akkaraekthali, P. Mu-near-zero metasurface for microstrip-fed slot antennas. Appl. Phys. A 2013, 112, 669-675.

13. Yuan, Y.; Zhang, K.; Ratni, B.; Song, Q.; Ding, X.; Wu, Q.; Burokur, S.N.; Genevet, P. Independent phase modulation for quadruplex polarization channels enabled by chirality-assisted geometric-phase metasurfaces. Nat. Commun. 2020, 11, 4186. [CrossRef] [PubMed]

14. Yuan, Y.; Sun, S.; Chen, Y.; Zhang, K.; Ding, X.; Ratni, B.; Wu, Q.; Burokur, S.N.; Qiu, C.-W. A Fully Phase-Modulated Metasurface as An Energy-Controllable Circular Polarization Router. Adv. Sci. 2020, 7, 2001437. [CrossRef] [PubMed]

15. Zhang, K.; Yuan, Y.; Ding, X.; Ratni, B.; Burokur, S.N.; Wu, Q. High-Efficiency Metalenses with Switchable Functionalities in Microwave Region. ACS Appl. Mater. Interfaces 2019, 11, 28423-28430. [CrossRef] [PubMed]

16. Yao, Y.; Liao, S.; Wang, J.; Xue, K.; Balfour, E.A.; Luo, Y. A new patch antenna designed for CubeSat: Dual feed, 1/s dual-band stacked, and circularly polarized. IEEE Antennas Propag. Mag. 2016, 58, 16. [CrossRef]

17. Pittella, E.; Pisa, S.; Pontani, M.; Nascetti, A.; D'Atanasio, P.; Zambotti, A.; Hadi, H. Reconfigurable S-band patch antenna system for CubeSat satellites. IEEE Aerosp. Electron. Syst. Mag. 2016, 31, 6-13. [CrossRef]

18. ANSYS HFSS Simulator. Available online: http://www.ansys.com/products/electronics/ansys (accessed on 12 October 2020).

19. Liu, X.; Jackson, D.R.; Chen, J.; Liu, J.; Fink, P.W.; Lin, G.Y.; Neveu, N. Transparent and Nontransparent Microstrip Antennas on a CubeSat: Novel low-profile antennas for CubeSats improve mission reliability. IEEE Antennas Propag. Mag. 2017, 59, 5968. [CrossRef]

20. Paiva, J.L.S.; Silva, J.P.; Campos, A.L.P.S.; Andrade, H.D. Using metasurface structures as signal polarisers in microstrip antennas. IET Microw. Antennas Propag. 2018, 13, 23-27. [CrossRef]

21. Chaimool, S.; Hongnara, T.; Rakluea, C.; Akkaraekthalin, P.; Zhao, Y. Design of a PIN Diode-Based Reconfigurable Metasurface Antenna for Beam Switching Applications. Int. J. Antennas Propag. 2019, 2019, 7216324. [CrossRef]

22. Naqvi, A.H.; Lim, S. Microfluidically Polarization-Switchable Metasurfaced Antenna. IEEE Antennas Wirel. Propag. Lett. 2017, 17, 2255-2259. [CrossRef]

23. Cao, Y.F.; Cheung, S.W.; Yuk, T.I. Performance Enhancement of Circular Polarization Reconfigurable Monopole Antenna Using Metasurface. In Proceedings of the 2016 10th European Conference on Antennas and Propagation (EuCAP), Davos, Switzerland, 10-15 April 2016.

24. El Bakkali, M.; Tubbal, F.; Gaba, G.S.; Kansal, L.; El Idrissi, N.E.A. S-Band CPW-Fed Slot Antenna with 2D Metamaterials for CubeSat Communications. In Communications in Computer and Information Science; Springer: Singapore, 2019; Volume 1076, pp. 344-356. [CrossRef]

25. Sitompul, P.P.; Sumantyo, J.T.S.; Kurniawan, F.; Nasucha, M. Axial Ratio and Gain Enhancement of a Circular-Ring Slot Antenna Using a Pair of Asymmetrical Rectangular Slots and a Parasitic Patch for a Radio Beacon on a Nanosatellite. Aerospace 2019, 6, 39. [CrossRef]

26. French South African Institute of Technology (F'SATI), CPUT (Cape Peninsula University of Technology). Available online: http:/ / www.cput.ac.za/blogs/fsati/zacube-2/ (accessed on 19 October 2020).

27. Earth Observation Portal, Satellite Missions: ZACUBE-2 (South African CubeSat-2). Available online: https://directory.eoportal. org/web / eoportal/satellite-missions / v-w-X-y-z/zacube-2 (accessed on 19 October 2020).

28. Squadrito, P.; Livreri, P.; Donato, L.D.; Squadrito, C.; Sorbello, G. A Telemetry, Tracking, and Command Antennas System for Small-Satellite Applications. Electronics 2019, 8, 689. [CrossRef]

29. Babuscia, A. Telecommunication Systems for Small Satellites Operating at High Frequencies: A Review. Information 2020, 11, 258. [CrossRef]

30. Shah, S.I.H.; Lim, S. A Dual Band Frequency Reconfigurable Origami Magic Cube Antenna for Wireless Sensor Network Applications. Sensors 2017, 17, 2675. [CrossRef] [PubMed]

31. Alam, T.; Islam, M.T.; Ullah, M.A.; Cho, M. A Solar Panel-Integrated Modified Planner Inverted F Antenna for Low Earth Orbit Remote Sensing Nanosatellite Communication System. Sensors 2018, 18, 2480. [CrossRef] [PubMed] 